\title{
A comparative techno-economic assessment of three bio-oil upgrading routes for aviation biofuel production
}

\author{
Stavros Michailos ${ }^{1}$ and Anthony Bridgwater ${ }^{2}$ \\ ${ }^{1}$ Department of Mechanical Engineering, The University of Sheffield, Western Bank, Sheffield S10 \\ 2TN, UK \\ ${ }^{2}$ School of Chemical Engineering \& Applied Chemistry, Aston University, Aston Triangle, Birmingham \\ Email: s.michailos@sheffield.ac.uk \\ B4 7ET, UK
}

\begin{abstract}
The aviation industry continues to grow and consequently more fuel is needed. With the intention of decarbonising the aviation sector, sustainable routes that have the potential to mitigate emissions, such as biomass fast pyrolysis, can positively contribute to this direction. Within this context, the present study performs a comparative techno-economic evaluation of aviation biofuel manufacture via the main bio-oil upgrading pathways, namely hydroprocessing (HP), gasification followed by Fischer-Tropsch synthesis (G+FT) and zeolite cracking (ZC). The research constitutes the first endeavour to investigate and compare the feasibility of producing biojet fuel via pyrolysis based routes.
\end{abstract}

The presented work provides an inclusive evaluation that comprises process modelling and financial assessment. Based on the simulations, overall energy efficiencies of $48.8 \%, 45.73 \%$ and $45.38 \%$ and jet fuel energy efficiencies of $23.70 \%, 21.45 \%$ and $20.53 \%$ were calculated, while the implementation of a discounted cash flow analysis estimated minimum jet fuel selling prices (MJSP) of 1.98, 2.32 and $2.21 \$ / L$ for the HP, the G+FT and the ZC respectively. Sensitivity analysis revealed that the processes are capital and feedstock intensive while an increase to the bio-oil yield will favour the economic performance of the examined biorefineries. An increase of the plant size from 100 (base case) to 150 dry tonnes per hour of feedstock will decrease the selling prices by approximately $25 \%$ for all cases. Monte Carlo simulations exhibited that without establishing and/or maintaining appropriate policy schemes there is no pragmatic prospect for the examined biorefineries to beat the competition against the prevailing oil infrastructures.

Keywords: aviation biofuel, fast pyrolysis, techno-economic analysis, process simulation, policy scenario 


\section{Introduction}

Aviation plays an important role in regard to the achievement of climate protection targets and will have to meaningfully contribute to the overall transformation of the society. Aviation is responsible for roughly $2 \%$ of the total manmade $\mathrm{CO}_{2}$ emissions and counts for $10 \%$ of total fuel consumption(1). In 2018, the aviation sector on a global basis consumed roughly 94 billion gallons of jet fuel in commercial flights (2). Fuel is the major operating expenditure in the air transport sector, and the volatile prices of crude oil hinder long-term scheduling and cost budgeting (3)(4). In theory, biomass derived aviation fuels can lessen the reliance of the aviation on one single feedstock, limit price oscillations associated with the volatility of crude oil prices, and potentially mitigate greenhouse gas (GHG) emissions (5)(6). Until now, commercial manufacture of biofuels has been impelled to a great extent by road transports. Nonetheless, these days a noteworthy interest has been exposed towards the manufacture of drop-in biojet fuels that are capable of entirely utilising the existing fuel infrastructures. Several available process routes exist for the synthesis of biojet fuel. These pathways are typically categorised depending on the feedstock and conversion routes as (7): (1) Hydroprocessed esters and fatty acids (HEFA), (2) Fischer-Tropsch synthesis (FT), (3) alcohol-to-jet (ATJ), (4) aqueous phase reforming (APR), (5) direct sugar to hydrocarbon (DSHC) and (6) hydrotreated depolymerised cellulosic jet (HDCJ). So far, six production pathways have been certified by the American Society for Testing and Materials (ASTM) for blending with conventional aviation fuel (8): Two production lines are based on the FT route namely the 1) FT-SPK (Fischer-Tropsch Synthetic Paraffinic Kerosene) and the 2) FT-SPK/A which is a variation of the FT-SPK where alkylation of light aromatics results in a hydrocarbon blend that comprises aromatic substances, 3) the HEFA, 4) the ATJ, 5) the DSHC, also known as HFS-SIP (Hydroprocessing of Fermented Sugars - Synthetic Iso-Paraffinic kerosene), and 6) co-processing of biocrude up to $5 \%$ by volume of lipidic feedstock in crude oil refinery units. The maximum blending ratio for the FT-SPK, FT-SPK/A, the HEFA and the ATJ is 50\% while for the DSHC is $10 \%$ (8).

Currently, biojet fuel productivity is limited due to the low demand on account of high prices. In 2018, the renewable prices were in the region of 3-4 times higher than the fossil jet fuel price (9). The major supplier of aviation biofuel is the HEFA process (10); a technology that has been proved on a commercial scale, principally for diesel production. Nevertheless, high feedstock costs and restricted availability of sustainable vegetable oil sources pose significant barriers that restrain the boost of HEFA technologies (11). Hence, it is crucial to design and implement novel biojet fuel conversion routes that would be able to operate at large scale and utilise sustainable feedstocks such as abundant lignocellulosics including agricultural wastes, forestry residues or municipal solid waste. As the investment in immature technologies comes at high risk, techno-economic analyses and comparisons 
of promising processes are vital to deliver better-quality predictions of the related costs and possible profits.

Fast pyrolysis can provide an efficient alternative to aviation biofuel production. During biomass fast pyrolysis process, the feedstock undergoes swift heating to a high temperature (around $500-600^{\circ} \mathrm{C}$ ) in an oxygen-free environment. Typically, on a mass basis fast pyrolysis produces $55 \%-70 \%$ of liquids with $15 \%-25 \%$ of solids (biochar) and $10 \%-20 \%$ of non-condensable gases, depending on the features of the biomass source (12). The yield of liquids is generally enhanced at modest temperature, increased heating rates and short resident time conditions while other key characteristics of the process include swift quenching of vapours and precise control of the temperature (13). Fast pyrolysis can make use of lignocellulosic feedstocks and display reasonably lower capital expenditures and higher thermodynamic efficiency than other processes, such as FT. Another advantage is that fast pyrolysis can yield aviation fuel that it is rich in aromatics and cycloparaffins and exhibits outstanding cold flow properties; hence an ideal blending substance with the FT-SPK and the HEFA jet fuel (14). Bio-oil cannot be utilised as it is as transportation fuel mainly because of its high acidity and increased oxygen content, and thereby upgrading is essential. Three are the main upgrading technologies i.e. hydroprocessing (HP), zeolite cracking (ZC) and gasification followed by FT synthesis $(\mathrm{G}+\mathrm{FT})(15)$. As a result of limited biomass availability, the formation of optimum biofuel value chains is a vital requirement for sustainable biofuel industries. In this manner, bioenergy plants will be able to exploit the economies of scale and maximise their financial potential.

In the past, several studies have examined the economic viability of renewable jet fuel. Based on a comprehensive literature review, it was concluded that most of the studies have dealt with the techno-economic assessment of HEFA, FT and ATJ routes. For instance, Wang (16) has studied the feasibility of producing hydroprocessed biojet fuels from Jatropha fruits. The MJSP was estimated at $\$ 1.43 / L$ for a plant size of 2400 metric tonnes per day. The National Renewable Energy Laboratory (NREL) in collaboration with the Pacific Northwest National Laboratory (PNNL) (17) assessed the feasibility of five biojet fuel processes based on routes utilizing oxygenated intermediates and FT technologies. The MJSP values for the oxygenated routes range between 1 and 1.48 \$/L. Sensitivity analysis revealed that MJSPs can be enhanced with co-product credits. Three different biorefineries were tested by Klein-Marcuschamer et al. (18) based on HEFA and DSHC technologies. The investigation indicated that biorefineries treating microalgae, pongamia seeds, and sugarcane feedstocks cannot beat the competition with fossil jet fuel resulting in MJSPs of 8.45, 2.35 and 1.89 $\$ / L$ respectively. Sensitivity studies of the main financial factors recommended technological and market advances that could drop the MJSPs down to $2.43,1.59$, and $1.06 \$ / \mathrm{L}$. Two biojet processes based on mixed alcohols synthesis were designed by Atsonios et al. (19) and promising results were 
obtained for both conversion routes. The jet fuel production rates are $0.138 \mathrm{~kg}$ of jet fuel per $\mathrm{kg}$ of dry feedstock when a modified $\mathrm{MeOH}$ catalyst is used and 0.112 in the case of a modified FT catalyst. An economic model was developed by Pearlson et al. (20) in order to evaluate the feasibility of producing aviation biofuel from soybean oil. The resultant MJSF is $1.07 \$ / L$ for a facility producing 21.2 $\mathrm{t} / \mathrm{h}$ of jet fuel. Diederichs et al. (21) investigated the economic performance of HEFA, gasification and fermentation based technologies aiming to compare $1 \mathrm{G}$ with $2 \mathrm{G}$ generation feedstocks; they concluded that $2 \mathrm{G}$ can be competitive with $1 \mathrm{G}$ technologies. A HEFA plant utilising as feedstock camelina oil was examined by Li et al. (22). The authors argue that the construction and the operation of such a plant in Canada could be feasible at a feedstock cost of approximately $0.43 \$ / \mathrm{L}$. Further studies that explore the feasibility of HEFA, FT and ATJ technologies can be found in (23)(24).

On the other hand, there is a lack of techno-economic assessments dealing with biokerosene production via biomass pyrolysis. Santos et al. (25) have explored the feasibility of integrating 1st (1G) with $2 \mathrm{nd}(2 \mathrm{G})$ sugarcane biorefineries and one scenario considered the utilisation of bagasse via fast pyrolysis followed by hydroprocessing for jet fuel production. Nevertheless, the study provided no detailed technical discussion regarding the pyrolysis step and comparisons with different bio-oil upgrading technologies was beyond the scope of the study. Yang et al. (26) carried out a detailed techno-economic assessment of a biojet fuel route via catalytic fast pyrolysis coupled with hydrogenation; they concluded that a relatively low jet fuel price of $3.78 \$$ /gallon can be achieved when cyclohexane is used as the medium for bio-oil hydrogenation. Nevertheless, the authors did not consider alternative upgrading techniques.

In consideration of the above, there is a gap in the literature regarding an inclusive investigation of the various pyrolysis based routes for biojet fuel production. To the best of our knowledge, the present research constitutes the first attempt to evaluate and compare the three main bio-oil upgrading technologies targeting to aviation biofuel production from lignocellulosic biomass.

\section{Materials and methods}

\subsection{Goal of the study}

The main objective of the current work is to conduct a holistic and comparative techno-economic assessment of the HP, G+FT and ZC alternatives. This was achieved via comprehensive process design and rigorous economic evaluation. The former was realised by developing process models within Aspen Plus software environment in combination with Excel spreadsheets and subsequently based on the simulations the purchased equipment were sized as well as energy and material streams were quantified. Economic evaluation incorporated the calculation of capital and operating expenditures along with the estimation of the minimum jet fuel selling price via a typical discounted cash flow 
analysis. Furthermore, in order to identify the key parameters influencing the MJSPs, a deterministic sensitivity analysis was conducted. Subsequently, Monte Carlo analysis was carried out aiming at quantitatively evaluating the cumulative uncertainty. Unlike deterministic techniques, probabilistic methods examine the uncertainty effect of the design parameters simultaneously. Finally, individual and combined effects of policy scenarios on the viability of the biorefineries were examined.

\subsection{Basis for process development}

Raw biomass, i.e. forest residue, is delivered to the plant at a rate of $100 \mathrm{dry}$ tonnes per hour $(\mathrm{dt} / \mathrm{h})$ or equally 800 dry kilotonnes per year ( $\mathrm{dkt} / \mathrm{y}$ ) and a moisture content of $40 \%$ (wet basis). Moderate scale fast pyrolysis plants, such as the Finish Fortum-Valmet plant that processes $100 \mathrm{dkt} / \mathrm{y}$ of forest residue (27) and the Dutch Empyro plant that processes $40 \mathrm{dkt} / \mathrm{y}$ of woody biomass (28), have gained enough operating experience. Nevertheless, no large scale plants have been built to date and since larger scale plants are needed for producing fuels so as to exploit the economies of scale (29), the present study examines the feasibility of a pyrolysis plant that it is roughly one order of magnitude larger than the biggest existing commercial plant, i.e. the Fortum-Valme.

A sequential-modular methodology is adopted wherein the balances governing each unit operation (block) are executed block-by-block in a step-by-step fashion. Afterwards, iterative methods are recruited to resolve the complications ascending from recycling the stream data. User determined non-conventional solids were selected to denote wood and ash. Intended to these components two Aspen Plus models were apportioned: one for the density (DCOALIGT) and one for the enthalpy (HCOALGEN) (30) that necessitate the knowledge of the proximate and ultimate analysis of the feedstock (see Table 1 (31)(32)). The physical properties of the conventional substances were calculated by utilising the Redlich-Kwong-Soave cubic equation of state with Boston-Mathias alpha function (RKS-BM)(33). The SOLIDS property model was utilised for the solids processing units (34), i.e. the size reduction and the drying operations, and lastly classic steam tables for the CHP components. The boundaries for all processes are the reception of biomass and storage of liquid fuels. The biorefineries are established within five steps: 1) biomass reception and pretreatment, 2) bio-oil production and recovery, 3) bio-oil upgrading to fuels, 4) utilities and 5) product fractionation and storage. These operations establish the inside battery limits (ISBL) area while the outside battery limits (OSBL) area comprises the balance of plant (BOP). The BOP includes the necessary infrastructures for grid and water networks. The utilities area involves the CHP system, the wastewater treatment unit and cooling towers. The wastewater plant along with the cooling towers were not explicitly simulated but were attributed a cost value. 
Table 1. Feedstock composition (31)(32)

\begin{tabular}{lc}
\hline \multicolumn{2}{c}{ Ultimate analysis (\%) } \\
\hline Element & Dry Weight \\
\hline $\mathrm{C}$ & 45.6 \\
$\mathrm{H}$ & 5.59 \\
$\mathrm{O}$ & 44.1 \\
$\mathrm{~N}$ & 0.75 \\
Ash & 3.96 \\
\hline \multicolumn{2}{c}{ Proximate analysis (\%) } \\
\hline Moisture & 40 (wet basis) \\
Ash & 3.96 (dry basis) \\
Volatile matter & 79.4 (dry basis) \\
Fixed carbon & 16.64 (dry basis) \\
\hline \multicolumn{2}{l}{ LHV } \\
\hline
\end{tabular}

The processes were designed to maximise jet fuel production. To this direction, hydrocrackers, that enhance kerosene-diesel yields, were employed to crack down heavy hydrocarbons instead of fluidised catalytic crackers that promote gasoline range fuels. The examined systems involve catalytic reactions; for the sake of straightforwardness it was assumed that catalysts are fully regenerated and are replaced every two years (19)(35)(36). Catalyst costs were estimated from space velocities and the reactor input flowrates. If not stated, carbon losses due to coke formation is accounted to the product distributions of the catalytic reactors. The yielded hydrocarbonaceous products were categorised, according to the carbon atoms, as: $C_{1}-C_{2} \rightarrow$ light gases, $C_{3}-C_{4} \rightarrow$ liquefied petroleum gas (LPG), $C_{5}-C_{7} \rightarrow$ Gasoline, $\mathrm{C}_{8}-\mathrm{C}_{16} \rightarrow$ Jet fuel, $\mathrm{C}_{17}-\mathrm{C}_{20} \rightarrow$ Diesel and $\mathrm{C}_{21}-\mathrm{C}_{30} \rightarrow$ Waxes. Finally, distillation columns were employed for product fractionation and they were simulated using the RadFrac unit operation model operating in equilibrium mode. Simplified process flow diagrams (PFDs) for the proposed biorefinery configurations are provided in Figure 1.

(Figure 1 here)

\subsection{Basis for cost estimation and DCFA}

A common discounted cash flow analysis (DCFA) was conducted so as to calculate the minimum fuel selling price. In the case of multiproduct generation, as in the present study, there are typically two ways to calculate the break-even fuel price (18): 1) the price of a single product is fluctuated whereas others are left constant, providing the price of that specific fuel; 2) the prices of the entire fuel spectrum are varied simultaneously. Since the target of the study is jet fuel production, the former method was applied with the intention of estimating the MJSP. The prices of gasoline and diesel are $0.43 \$ / L$ and $0.44 \$ / L$ respectively (average 2017)(37). The location of the biorefineries is US Gulf coast, the reference year of the study is 2017 and the currency is USD. The Chemical Engineering Plant 
Cost Indices (CEPCI) were utilised to update CAPEX. The techno-economic assessment as defined here involves what are labelled as " $n$ th-plant" economics. The principal assumption of " $n$ th-plant" economics is that the investigation does not consider a pioneer plant; alternatively, it assumes that numerous plants utilising identical technologies have already been constructed and operating. The first step of the DCFA is the estimation of the equipment cost. The scaling exponent method, as given in Eq.(1)(38), is employed to calculate the equipment costs:

$C=C_{0}\left(\frac{s}{s_{0}}\right)^{f}$

Where:

$C$ is the actual cost, $C_{0}$ is the base cost

$S$ is the actual size

$S_{0}$ is the capacity

$f$ an emirical scaling factor

The values of $C_{0}, S_{0}$ and $f$ have been extracted from relevant literature (39)(40)(41)(42)(43) and they are presented in Appendix A, Table A.1. In particular, Albrecht et al. (42) and Lauven et al. (43) have comprehensively collected and tabulated data related to equipment costs for biorefinery solutions and their studies were the main source of the equipment cost data. The factorial method is employed to estimate the total capital investment (TCI). The latter includes ISBL, OSBL, indirect costs and working capital. As mentioned before, the OSBL counts only for the BOP and thereby a relatively low cost value was attributed, i.e. $12 \%$ of the ISBL. The complete approach for the estimation of $\mathrm{TCl}$ is explained in Appendix A, Table A.2 (38)(44)(45).

In addition, Table 2 (35)(40)(46)(47)(48)(49)(50)(51) presents the variable OPEX while Table A.3 (41)(52)(53) in Appendix A provides the methodology for estimating the fixed operating costs. The labour requirement is calculated by employing the following correlation (refers to fully automated processes)(54):

$N_{O L}=\left(6.29+31.7 P^{2}+0.23 N\right)^{0.5}$

Where:

$N_{O L}$ is the operators number

$P$ is the number of the solids handling units

$N$ is the number of the nonparticulate process units

For every single of the $N_{O L}$ labourers, around 5 labourers should be appointed for a unit that operates 24 hours per day, to make allowance for 3 daily shifts in addition to ordinary and sick yearly leaves. Furthermore, a yearly salary of $\$ 60,000$ was assumed (55). 
Table 2. General variable costs for processing biomass feedstock

\begin{tabular}{l|ccc}
\hline Parameter & Price & Unit & Reference \\
\hline Feedstock price & 90 & $\$ / \mathrm{dt}$ & Assumption \\
Electricity price & 0.07 & $\$ / \mathrm{kWh}$ & Assumption \\
Ruthenium catalyst & 60 & $\$ / \mathrm{kg}$ & $(35)$ \\
Molybdenum catalyst & 30 & $\$ / \mathrm{kg}$ & $(35)$ \\
Zeolite catalyst & 310 & $\$ / \mathrm{kg}$ & $(40)$ \\
Cooling water & 0.025 & $\$ / \mathrm{t}$ & $(46)$ \\
Feed boiler water & 1 & $\$ / \mathrm{t}$ & $(46)$ \\
Ash disposal & 25.8 & $\$ / \mathrm{t}$ & $(47)$ \\
Waste water disposal & 0.53 & $\$ / \mathrm{t}$ & $(48)$ \\
Nickel catalyst & 35.36 & $\$ / \mathrm{kg}$ & $(48)$ \\
Sulfided catalyst & 56.29 & $\$ / \mathrm{kg}$ & $(49)$ \\
Cobalt catalyst & 35.36 & $\$ / \mathrm{kg}$ & $(50)$ \\
Oxygen & 117 & $\$ / \mathrm{t}$ & $(51)$ \\
\hline
\end{tabular}

For all cases, the adopted finance scheme considers a 50-50 debt-equity contribution. Subsequently, the weighted average cost of capital (WACC) is given as (56):

$W A C C=D R \times i_{d}+\left[(1-D R) \times i_{e}\right]$

Where:

$D R$ is the debt ratio

$i_{d}$ is the inrest rate due to debt and

$i_{e}$ is the cost of equity

In theory, the WACC constitutes a decent substitute for the discount rate and this assumption was adapted in the present study in order to budget the examined ventures and conduct the DCFA. The tax rate for 2017 is $40 \%$ (57) and includes both federal and state taxes. The key economic parameters and assumptions are tabulated in Table 3.

Table 3. Economic parameters and assumptions for the DCFA

\begin{tabular}{lc}
\hline Parameter & Value \\
\hline Location & US Gulf coast \\
Base year & 2017 \\
Project lifetime (years) & 20 \\
Construction period & 3 \\
CAPEX allocation during the construction period & $30 \%, 60 \%, 10 \%$ \\
Operating hours (hours/year) & 8000 \\
Tax rate (\%) & 40 \\
Equity/Debt (\% / \%) & $50 / 50$ \\
Debt interest (\%) & 6 \\
Debt payment (years) & 10 \\
Return on Equity (\%) & 12 \\
WACC (\%) & 9 \\
Depreciation & straight-line \\
Depreciation period (years) & 10 \\
\hline
\end{tabular}




\section{Process design and simulation}

\subsection{Feedstock reception and pretreatment}

The reception area involves several operations including the feedstock delivery by means of road transportation (trucks), storage units and conveyors. More details regarding the reception step have been discussed before and can be found in (58)(59).

Thereafter, biomass is fed to a series of two gyratory grinders, which serve to reduce feedstock to the required size for fluidised bed pyrolysis $(2 \mathrm{~mm})$. Such a small size is essential in order to sustain high heat transfer rates. The electricity consumption of the grinders is taken as $50 \mathrm{kWh}$ per tonne of dry feed (29). Chopped biomass is then sent to the drying unit. The high initial moisture content of the feedstock makes it essential to engage a dryer so as to limit the heat losses in the pyrolysis unit and increase efficiencies. Andersson et al. (60) assessed three different drying technologies - steam drying, flue gas drying and vacuum drying - by means of pinch analysis in order to integrate them with a pulp mill. It was concluded that the flue gas utilisation was the most efficient alternative and this approach was utilised in the present work assuming that similar results should be expected in a biorefinery plant. The energy requirements of the process for reducing moisture content to $10 \%$ are $2.5 \mathrm{MJ}_{\mathrm{th}} / \mathrm{kg}$ of $\mathrm{H}_{2} \mathrm{O}$ evaporated; to account for the energy needed to heat the biomass and the heat losses to the environment, an additional $50 \%$ of thermal energy is necessary (61). In addition, the electricity demand of the biomass drying unit is taken as $0.28 \mathrm{MJ} / / \mathrm{kg}$ of $\mathrm{H}_{2} \mathrm{O}$ evaporated (61). The dryer was modelled using a RSTOICH reactor while for simulation purposes a flash drum was used to remove the exhaust moisture.

\subsection{Bio-oil production and recovery}

The dried, finely ground biomass is fed to the pyrolysis reactor operating at $500^{\circ} \mathrm{C}$, atmospheric pressure and vapour residence time of less than 2 seconds. A circulating fluidized bed was selected as reactor configuration in this study as this design is the most probable to be scaled up to the presumed feed rate (36). The feedstock is transformed into a mixture of vapours and solids. Medium pressure steam generated in the CHP unit is utilised as fluidising agent at a steam to biomass mass ratio of 0.5 (62) while sand (simulated as Silicon dioxide) serves as heating carrier at a weight ratio of 20 (63). The necessary heat for the pyrolysis is supplied by means of char combustion. The heat demand for the endothermic pyrolysis reactions was estimated equal to $1.5 \mathrm{MJ} / \mathrm{kg}$. Rogers and Brammer (64) mention an additional requirement of $0.3 \mathrm{MJ} / \mathrm{kg}$ for the evaporation of any remaining moisture in the feedstock and another $0.6 \mathrm{MJ} / \mathrm{kg}$ for elevating the temperature of the fluidising gas as well as an allowance of 
$3 \%(65)$ of the heat input to the pyrolyser to account for heat losses; therefore, the overall heat demand of the pyrolysis reactor is $2.47 \mathrm{MJ} / \mathrm{kg}$.

The pyrolyser was modelled by employing two RYIELD reactors. The first reactor decomposes biomass to its constituent elements based on the ultimate analysis while the second one provides the pyrolysis products. The generic product distribution is as follows: 1) Bio-oil $\rightarrow 61 \%$ (wet), 2) Char (solid carbon and ash) $\rightarrow 24 \%$ and 3 ) Gases $\rightarrow 15 \%$. A FORTRAN calculator block fixes the detailed product distribution according to Table 4 (31). The data in Table 4 is derived from lab-scale results of forest residues pyrolysis (31). Afterwards, the pyrolysis products have to be separated. A series of cyclones (two in total) is utilised to recover solid carbon and sand from the vapours and then an electrostatic precipitator (modelled as a common separator assuming a $100 \%$ efficiency) to remove the ash. A series of heat exchangers (four in total) serve to cool down the pyrolysis output vapour stream resulting in condensation of the tars. The liquid phase is distinguished from the non-condensable gases via a typical flash drum. Bio-oil is generated at a rate of $61 \mathrm{t} / \mathrm{h}$ (a 100\% recovery was considered), solid carbon at $22.3 \mathrm{t} / \mathrm{h}$ and gases at $14 \mathrm{t} / \mathrm{h}$.

\begin{tabular}{|c|c|}
\hline Product & Wt.\% \\
\hline Gases & 15 \\
\hline $\mathrm{CO}$ & 6.24 \\
\hline $\mathrm{CO}_{2}$ & 4.59 \\
\hline $\mathrm{CH}_{4}$ & 2.1 \\
\hline $\mathrm{H}_{2}$ & 2.07 \\
\hline Liquids & 61 \\
\hline Acetic acid & 12.33 \\
\hline Guaiacol & 2.21 \\
\hline Syringol & 3.68 \\
\hline Formic acid & 8.59 \\
\hline Propyl benzoate & 23.04 \\
\hline Phenol & 2.36 \\
\hline Toluene & 5.35 \\
\hline Furfural & 25.67 \\
\hline Benzene & 1.79 \\
\hline Water & 15 \\
\hline Char & 24 \\
\hline Solid carbon & 20.04 \\
\hline Ash & 3.96 \\
\hline
\end{tabular}




\subsection{Upgrading section}

\subsubsection{Hydroprocessing}

The oxygen content in the bio-oil has to be decreased to negligible levels in order to meet the transportation fuel standards. During hydroprocessing, the bio-oil reacts catalytically with hydrogen and oxygen is rejected in the form of water, $\mathrm{CO}_{2}$ or $\mathrm{CO}$. The required amount of hydrogen for the biooil hydrogenation is equal to $0.06 \mathrm{~kg}$ per $\mathrm{kg}$ of bio-oil (36). Hydrogen is produced from the pyrolysis gases as well as from the light gases and part of the gasoline ( $10 \%)$ both derived from the fractionation columns. Hydrogen generation is achieved in a three step conversion route based on reforming reactions. Initially, a pre-reformer is employed to produce a mixture of syngas $\left(\mathrm{CO}+\mathrm{H}_{2}\right)$ and methane from the hydrocarbons. The pre-reformer operates at $500^{\circ} \mathrm{C}$ and 23 bar and the steam to carbon ratio is 2.4. Then a typical steam methane reformer (SMR) converts methane to syngas over nickel based catalysts and operates at $950^{\circ} \mathrm{C}$ and 22 bar(66). The final conversion step is to shift $\mathrm{CO}$ to $\mathrm{CO}_{2}$ and water to $\mathrm{H}_{2}$ in a typical water gas shift reactor (WGSR). The reactors were simulated using REQUIL reactors while the necessary steam is supplied from the quenching units. Gas hourly space velocities (GHSV) for SMR and WGSR are 2600 and $1000 \mathrm{~h}^{-1}(66)$ respectively. Finally, $\mathrm{H}_{2}$ is recovered via a pressure swing adsorption (PSA) unit (simulated as a simple separation unit with a fixed recovery efficiency of 90\%) and the off gases are fed to the CHP unit.

The oxygen removal process is done via a three-stage hydrotreating configuration (39). During the first phase (stabiliser), hydrotreating takes place in relatively moderate conditions of $143^{\circ} \mathrm{C}$ and 83 bar to stabilise the pyrolysis liquid. The second phase, i.e. $1^{\text {st }}$ high pressure bed (HPB) is a process that necessitates severer conditions of $190^{\circ} \mathrm{C}$ and 141 bar. The 3 rd stage $\left(2^{\text {nd }} \mathrm{HPB}\right)$ finalises the conversion of the bio-oil to hydrocarbons and operates at $350^{\circ} \mathrm{C}$ and $150 \mathrm{bar}$. The stabiliser operates at a liquid hourly velocity of $0.5 \mathrm{~h}^{-1}$ while the subsequent high pressure steps at $0.22 \mathrm{~h}^{-1}$ (39). Several, deoxygenation reactions occur in the hydrotreaters, including hydrodeoxygenation, decarboxylation and decarbonylation which reject oxygen as water, $\mathrm{CO}_{2}$ and $\mathrm{CO}$ respectively. The first and the second stage operate over ruthenium based catalysts while molybdenum based catalysts have been suggested for the final stage (35). The ruthenium catalysts are regenerated after being washed with solvent and contacted with steam at around $600^{\circ} \mathrm{C}$. Regeneration of molybdenum catalyst is also necessary due to coke deposition and it is accomplished in air at about $600^{\circ} \mathrm{C}$, trailed by a mild treatment in aqueous ammonia to enhance the activity of the catalyst (67). The catalyst regeneration units were not part of the modelling efforts but they were considered to the economic evaluation.

The product distribution on a mass basis of the upgrading section is: hydrocarbons $\rightarrow 33 \%$, water $\rightarrow 45 \%$ and gases $\rightarrow 22 \%$ based on wet bio-oil feed. The gas product consists of $\mathrm{CO}, \mathrm{CO}_{2}$ and light alkanes and 
is fed to the hydrogen production area. The hydrocarbons stream heads to common refinery units where gasoline, jet fuel, diesel and wax ( $5 \%)$ are recovered in a series of three distillation units. The wax product is pumped to $50 \mathrm{bar}$ and undergoes heating to $380^{\circ} \mathrm{C}$ and subsequently it is fed to a hydrocracking unit (sulfided platinum catalyst). A complete wax conversion was assumed whereas the necessary hydrogen counts roughly for $1.5 \% \mathrm{w} / \mathrm{w}$ of the feed stream. The product distribution on a mass basis for the hydrocracking unit is set to $50 \%$ for jet fuel, $30 \%$ for diesel, $15 \%$ for gasoline and $5 \%$ for light gases (68). The hydrocracker product stream is recycled to the refinery units for fractionation. In addition, the hydrocracker catalyst is regenerated through oxidisation at elevated temperatures to burn off carbonaceous materials (67). Modelling of catalytic reactors was based on published values for carbon yields to product "classes" (RYIELD reactors) instead of comprehensive kinetics or rate expressions. This uncomplicated stoichiometric approach can still satisfy mass and energy balances adequately, and can deliver a comprehensive foundation for techno-economic evaluations.

\subsubsection{Gasification followed by Fischer-Tropsch}

The concept of this upgrading method is that the bio-oil is gasified to give rise to syngas which, after being conditioned, is converted to a syncrude via FT reactions. An entrained flow gasifier, working at high temperature $\left(=1500^{\circ} \mathrm{C}\right)$ and pressure of $20 \mathrm{bar}$, was considered herein as it can achieve high conversion efficiency and good gas quality (low tar concentrations and little methane)(69) (70). In addition, gasifiers operating at elevated pressures are more suitable for fuel production as the pressure of the syngas will be adequate or will require marginal increase to meet the operating pressure of typical synthesis reactors. Pure oxygen instead of air is utilised as oxidising agent since it decreases the capital charges from reduced equipment sizes and also rises the syngas heating value. The equivalence ratio was set equal to 0.4 and oxygen is purchased from an external supplier.

Bio-oil does not require preheating as this could result in degrading bio-oil to char due to elevated temperatures. The producer gas, primarily consisting of $\mathrm{CO}, \mathrm{CO}_{2}, \mathrm{H}_{2}$ and $\mathrm{H}_{2} \mathrm{O}$ (see Table 4), is expected to be free from ash as bio-oil is reasonably clean, especially when compared to solid biomass feedstocks (71). A modelling approach frequently used for predicting the composition of biomass gasification producer gas is by calculating the thermodynamic equilibrium composition via Gibbs free energy minimisation estimations for the $\mathrm{C}, \mathrm{H}$, and $\mathrm{O}$ atoms of the biomass and the oxidising agent. This technique was adapted before in numerous works $(70)(72)$ and it is well suited for technoeconomic assessments but not for detailed reactor design. In addition, as reported in (73) chemical equilibrium is a suitable and reliable technique when modelling entrained-flow gasifiers in chemical process simulators. Thus, the present study employs an RGIBBS reactor to model the gasification 
process and predict the syngas composition. Prior to the FT synthesis, the $\mathrm{H}_{2}: \mathrm{CO}$ ratio has to be adjusted to 2.1 and thereby a water gas shift reactor $\left(T=600^{\circ} \mathrm{C}\right.$ and $\mathrm{P}=20$ bar $)$ is utilised for this purpose (50). Hot gases are then cooled down, in a series of heat exchangers (five in total), to a final temperature of $80^{\circ} \mathrm{C}$; ideal for the following syngas conditioning units and water removal. The cooling section gives rise to medium pressure saturated steam (10 bar) that acts as heating utility. Thereafter, a typical MEA absorber-stripper configuration is employed to remove $\mathrm{CO}_{2}$ from the syngas with heating requirements equal to $3.5 \mathrm{MJ}$ per $\mathrm{kg}$ of $\mathrm{CO}_{2}$ captured (74).

The next step of the process is the FT reaction unit where the governing catalytic reaction schemes can be summarised as follows:

Olefins: $n \mathrm{CO}+2 \mathrm{nH}_{2} \rightarrow \mathrm{C}_{n} \mathrm{H}_{2 n}+\mathrm{nH}_{2} \mathrm{O}$

Paraffins: $n \mathrm{CO}+(2 n+1) \mathrm{H}_{2} \rightarrow \mathrm{C}_{n} \mathrm{H}_{2 n+2}+(n-1) \mathrm{H}_{2} \mathrm{O}$

The mass fractions of the FT products can be approximated by utilising the Anderson-Schultz-Flory model, Eq. (6), provided that the chain growth factor, $a$, remains constant (75). In general, the higher the value of the chain growth factor is (upper limit is 1 ), the more heavy the yielded hydrocarbons are. To enhance the yield of middle distillates a value of $a$ equal to 0.9 is satisfactory (see Figure 2). Slurry reactors with cobalt based catalysts have been suggested (76) as the best choice to maximise the kerosene-diesel product fraction and as such this configuration was selected here.

$\frac{W_{n}}{n}=(1-\alpha)^{2} \alpha^{(n-1)}, W=$ product mass fraction and $n=$ number of carbon atoms

The conditioned syngas is pressurised via compression ( $25 \mathrm{bar}$ ) and heated $\left(212^{\circ} \mathrm{C}\right.$ ) prior to the FT reactor. A product distribution reactor (RYIELD) that fixes the exit mass yields of the products, according to Eq. (6), was employed to model the FT unit. An interface was established between Aspen Plus and an Excel spreadsheet to model the reactor; mass balances were executed in Excel and results were transferred to Aspen Plus. The per pass conversion of CO was set equal to $40 \%$ and a GHSV of $100 \mathrm{~h}^{-1}$ was considered (66). The regeneration of a spent cobalt based FT catalyst can be realised by employing a process that includes solvent wash to eradicate excess wax and oxidation to eliminate residual carbon (67). Subsequently, the product stream undergoes cooling and a common gas liquid separator is utilised to distinguish the hydrocarbons from the unconverted syngas. The latter is sent to a PSA unit to recover $\mathrm{H}_{2}$ that will be utilised for processing the olefins and the waxes, and subsequently the off gases are recycled to the WGSR. In order to avert accumulation a small portion ( $10 \%)$ of the unconverted syngas is purged to the CHP unit.

In turn, the liquid product is subjected to upgrading. First the olefins in the hydrocarbon mix react with hydrogen to form paraffins. For modelling purposes, it was assumed that the ratio of paraffin/olefin 
mole ratio of all hydrocarbons produced in the FT reactions is $0.7: 0.3$ (77). The reactor operates at $350^{\circ} \mathrm{C}$ and $35 \mathrm{bar}$ and the conversion rate of olefins to paraffins is assumed complete. Furthermore, the wax stream after being recovered from the rest of the hydrocarbons in a series of two distillation columns, it is pressurized to 50 bar and heated up to $380^{\circ} \mathrm{C}$ and enters a hydrocracking unit (assumptions and operating parameters were previously discussed). The cracked stream is recycled to the distillation units to fractionate the products i.e. gasoline, jet fuel and diesel.

(Figure 2 here)

\subsubsection{Zeolite cracking}

Zeolite (HZSM-5) cracking removes oxygen as $\mathrm{CO}_{2}$ and mostly yields aromatic hydrocarbons, but with considerable coke deposition on the catalyst. Bio-oil is introduced to the catalytic fluidised bed after being preheated to $283^{\circ} \mathrm{C}$ by a fired heater. Kinetic models for the zeolite cracking reactions are complex and often lack reliability. Therefore, a similar approach to the HP route is adopted again and a fixed product distribution was defined in a RYIELD unit as follows (78)(79): hydrocarbons $\rightarrow 28 \%$, water $\rightarrow 48 \%$, gases $\rightarrow 6 \%$ and coke $\rightarrow 18 \%$. The product distribution is based on the experiments conducted by Sharma and Bakhsh (78), and Adjaye et al. (79). The experiments were conducted at $283^{\circ} \mathrm{C}$ and weight hourly space velocity (WHSV) of $3.6 \mathrm{~h}^{-1}$.

The stream exiting the reactor is sent to the conditioning section. Initially, a series of cyclones is employed with the aim of recovering the entrained catalyst particles from the vapour stream (overall efficiency equal to $100 \%$ ) and then, two coolers in series serve to cool down the vapour stream to $40^{\circ} \mathrm{C}$. The Laumonite model component is chosen to represent zeolites owing to similar physical properties (40). Thereafter, a typical flash drum operating at atmospheric pressure is employed to separate the quenched stream in three phases, i.e. non-condensable gases ( $\mathrm{CO}$ and $\mathrm{CO}_{2}$ ), water and organics. The gases are sent to the CHP island and the organics to the refinery units for product fractionation (two distillation units were utilised).

It should be also noted that since there is no need for hydrogen production, the non-condensable gases produced during pyrolysis are fed to the CHP unit. Regarding catalyst regeneration, a two stage process was considered which implicates coke combustion in two steps (40). Initially, coke is partially combusted at $750^{\circ} \mathrm{C}$ in an environment that is air-deficient and at a stoichiometric air-to-coke ratio of 0.55 (40). The catalyst is recovered with a cyclone and recycled to the zeolite reactor. The exhaust gas from the first regenerator unit, which is rich in $\mathrm{CO}$ content, heads to the second regenerator unit to 
submit to complete combustion at $1550^{\circ} \mathrm{C}$. The flue gas from the 2 nd combustor is sent to the $\mathrm{CHP}$ unit to raise superheated steam for power generation.

\subsection{Heat and power generation island}

A combustion chamber, operating at $1800^{\circ} \mathrm{C}$ and atmospheric pressure, burns solid carbon and gases (pyrolysis and/or process) in excess air (15\%) to produce $\mathrm{CO}_{2}$, water vapour and heat. The latter is transferred to the pyrolyser by circulating sand and in this way the pyrolysis temperature is maintained at $500^{\circ} \mathrm{C}$. Due to software limitations, the sand loop was not properly simulated and heat transfer to the pyrolyser was achieved by employing a heat exchanger, and a heat stream rather than a material enters the reactor. Flue gases raise high pressure steam $\left(550^{\circ} \mathrm{C}\right.$ and $\left.110 \mathrm{bar}\right)$ in a series of heat exchangers (economiser, evaporator and superheater) which subsequently drives steam turbines (high, medium and low pressure) to generate electricity. It should be noted that the flue gases serve first heating duties at temperatures above $250^{\circ} \mathrm{C}$ before raising superheated steam. The isentropic and mechanical efficiencies of the steam/gas turbines were taken as $88 \%$ and $95 \%$ respectively (80). Steam turbines generate high, medium and low pressure steam. Part of the low pressure steam is utilised to meet the heating demand of each procedure so as to ensure energy autonomy. The low pressure steam leaving the turbine section is condensed and recirculated via pumps to the heaters. Flue gases exit the heat recovery unit at approximately $120^{\circ} \mathrm{C}$ and provide the necessary heat for the biomass drying.

\section{Results}

\subsection{Technical indicators}

This section presents the basic mass and energy efficiencies for each process. Table 5 summarises the mass yields of the intermediates, the overall hydrocarbon products and the jet fuel. The HP alternative achieves the higher productivity values followed by $\mathrm{G}+\mathrm{FT}$. The latter comprises more process steps and as so lower yields are attained. The major bottleneck of the G+FT is the low single pass conversion of the $\mathrm{CO}$ in the FT reactor that limits the overall CO conversion to $80 \%$ (achieved after stream recycling). Regarding the ZC case, productivities suffer since a large portion of the biomass carbon content is deposited as coke or rejected as $\mathrm{CO}_{2}$. The carbon balance across the processes shows that merely $1 / 3$ of the available carbon remains in the final products mainly because of $\mathrm{CO}_{2}$ production in many process segments including the pyrolysis, gasification, cracking and hydrogenation units, water gas shift as well as char and tail gas combustion.

A key challenge for any biojet fuel production route is the necessity of using hydrogen in the upgrading section. As already discussed, hydrogen is utilised to saturate olefins, remove oxygen and crack down 
heavy hydrocarbons. Table 6 depicts the hydrogen demand of each route along with the source it is derived from. The HP requires the highest amounts of $\mathrm{H}_{2}$ and in order to meet this demand a portion of the produced hydrocarbons, i.e. the entire amount of light $\mathrm{H} / \mathrm{C}$ and $10 \%$ of the gasoline stream, has to be sacrificed and reformed to $\mathrm{H}_{2}$. The G+FT process meets the demand with $\mathrm{H}_{2}$ recovered from the unconverted syngas exiting the FT reactor after proper PSA separation as discussed in the 3.3.2 section. It should be noted that the production or the recovery of the required $\mathrm{H}_{2}$ were designed in such a manner so as to match the demand. Alternative ways to generate $\mathrm{H}_{2}$ include water electrolysis and methane reforming but the inclusion of such units would significantly increase production costs and challenge the sustainability of the biorefineries (as electricity and methane should be of renewable origin). 
Table 5. Detailed intermediate and final product yields for each conversion route

\begin{tabular}{|c|c|c|c|c|c|c|c|c|c|c|}
\hline Process & Feedstock & $\begin{array}{l}\text { Intermediate } \\
\text { product } 1\end{array}$ & $\begin{array}{l}\text { Intermediate } \\
\text { product } 1 \text { yield } \\
\text { (g/g dry } \\
\text { feedstock \%) }\end{array}$ & $\begin{array}{l}\text { Intermediate } \\
\text { product } 2\end{array}$ & $\begin{array}{l}\text { Intermediate } \\
\text { product } 2 \text { yield } \\
(\mathrm{g} / \mathrm{g} \\
\text { intermediate } 1 \\
\%)\end{array}$ & $\begin{array}{l}\text { Hydrocarbon yield } \\
\text { (g/g intermediate } 1 \\
\text { or } 2 \% \text { ) }\end{array}$ & $\begin{array}{l}\text { Jet fuel yield (g/g } \\
\text { Hydrocarbon \%) }\end{array}$ & $\begin{array}{l}\text { Overall } \\
\text { Hydrocarbon } \\
\text { yield (g/g dry } \\
\text { feedstock \%) }\end{array}$ & $\begin{array}{l}\text { Overall jet } \\
\text { yield (g/g } \\
\text { dry } \\
\text { feedstock } \\
\%)\end{array}$ & $\begin{array}{l}\text { Carbon } \\
\text { efficiency } \\
\text { (\%) }\end{array}$ \\
\hline HP & $\begin{array}{l}\text { Forest } \\
\text { residue }\end{array}$ & Bio-oil & $61 \%$ & - & - & $32.10 \%$ & $50 \%$ & $19.58 \%$ & $9.79 \%$ & 34 \\
\hline $\mathrm{G}+\mathrm{FT}$ & $\begin{array}{l}\text { Forest } \\
\text { residue }\end{array}$ & Bio-oil & $61 \%$ & FT fuels & $31.10 \%$ & $93.40 \%$ & $49 \%$ & $17.72 \%$ & $8.68 \%$ & 31 \\
\hline ZC & $\begin{array}{l}\text { Forest } \\
\text { residue }\end{array}$ & Bio-oil & $61 \%$ & - & - & $27.80 \%$ & $48 \%$ & $16.96 \%$ & $8.14 \%$ & 30 \\
\hline
\end{tabular}

Table 6. Hydrogen demand for each alternative

\begin{tabular}{cccc}
\hline Process & $\begin{array}{c}\text { Hydrogen demand } \\
(\mathrm{kg} / \mathrm{h})\end{array}$ & $\begin{array}{c}\text { Hydrogen demand (kg per } \\
\text { tonne of hydrocarbon product) }\end{array}$ & Hydrogen source \\
\hline HP & 3660 & 186.9 & On site reforming \\
G+FT & 410 & 23.1 & From the FT unit \\
ZC & - & - & - \\
\hline
\end{tabular}


In process engineering, energy quantitative appraisal can be conducted by using the first law of thermodynamics. This energetic assessment has the potential to serve as a reliable basis for comparisons between individual components or whole systems in order to foster informed decision making. It should be highlighted that all processes are energy autonomous both in heating and electricity terms. Any excess of electricity is sold to the grid. Therefore, the overall energy efficiency of the system is calculated by utilizing Eq. (7). In addition, jet fuel efficiency was estimated as defined in Eq. (8).

$\eta_{\text {overall }}=\frac{\dot{m}_{\text {fuel }} L H V_{\text {fuels }}+W}{\dot{m}_{\text {feedstock }} L H V_{\text {feedstock }}}$

$\eta_{\text {jetfuel }}=\frac{\dot{m}_{\text {jetfuel }} L H V_{\text {jetfuel }}}{\dot{m}_{\text {feedstock }} L H V_{\text {feedstock }}}$

Where $\dot{m}_{f u e l}$ and $\dot{m}_{\text {feedstock }}$ are the mass flow rates of the fuel products and the feedstock respectively while $W$ refers to excess power generation. Surplus electricity productions are 4.1, 7.5 and $11.2 \mathrm{MW}$ for the $\mathrm{HP}, \mathrm{G}+\mathrm{FT}$ and $\mathrm{ZC}$ respectively while the main electricity consumer for all cases is the pretreatment area and in particular the grinders. Even if the energy efficiencies are very close, it is apparent from Figure $\mathbf{3}$ that the increased yields of the liquids products associated with the HP scenario favour energy efficiency compared to the augmented power generation that is related to the G+FT and ZC cases. Increased electricity productions are reported for these pathways because pyrolysis gases are utilised as burn fuel while for the HP case they serve as $\mathrm{H}_{2}$ source. Similar trend is observed when only jet fuel is considered as product and as such the HP route outplays the competitors.

\section{(Figure 3 here)}

\subsection{Economic indicators}

Initially, an overall scaling factor for each case was calculated by varying the feedstock input rate from $25 \mathrm{dt} / \mathrm{h}$ to $200 \mathrm{dt} / \mathrm{h}$. The calculated values, i.e. 0.68 for the HP, 0.7 for the $\mathrm{ZC}$ and 0.69 for the $\mathrm{G}+\mathrm{FT}$ (see Figure 4), align with the value documented by Couper (52) for complete plants, i.e. 0.7. This analysis enables future designers to obtain initial TCl estimates of similar technologies without the necessity of collecting individual equipment data.

\section{(Figure 4 here)}

In addition, Figure $\mathbf{5}$ provides the breakdown of the capital costs by process functional unit as a percentage of the purchased equipment cost (PEC). It should be noted here that the CHP units include 
heat recovery systems, compressors, gas and steam turbines as well as auxiliary equipment. The HP and G+FT alternatives involve more process steps than the ZC plant and this consequently increases the complexity and the capital investment costs. The TCI for the HP and the G+FT are very close, i.e. $1085 \mathrm{M}$ and $1095 \mathrm{M} \$$ respectively. The major cost driver of the HP route is the hydroprocessing unit followed by the hydrogen production plant while for the G+FT the main contributors are the gasification island along with the CHP unit. A total investment of approximately $950 \mathrm{M} \$$ is required for the ZC plant; the zeolite cracking reactor accounts for roughly $40 \%$ of the capital expenditures. Furthermore, for all cases, feedstock prices account for approximately $50 \%$ of the OPEX while maintenance costs for $19-22 \%$. Other significant cost drivers differ based on the particularity of each alternative. Therefore, for the HP option the hydrotreating catalysts are responsible for approximately $10 \%$ of the OPEX, for the G+FT the required oxygen for the gasification unit corresponds to $8 \%$ and for the ZC technology the zeolite catalyst costs contribution is as high as $17 \%$. Finally, labours costs do not exceed $7 \%$ for all cases. Figure 6 presents a detailed itemisation of the OPEX for each biorefinery.

\section{(Figure 5 here)}

(Figure 6 here)

Subsequent to the estimation of CAPEX and OPEX, it was possible to calculate the MJSP for each alternative. Based on the capital expenditures and the annual cash flows, the break-even NPV of each project was estimated. The economic evaluation projected MJSPs of $1.98 \$ / L, 2.32 \$ / L$ and $2.21 \$ / L$ for the $\mathrm{HP}, \mathrm{G}+\mathrm{FT}$ and $\mathrm{ZC}$ respectively. As depicted in Figure 7, these prices are 4.8-5.4 times higher than the fossil jet fuel price, i.e. $0.41 \$ / L$ (average 2017) (37). Therefore, it is apparent that strong policy support is necessary to enhance the viability of the biorefineries. Table $\mathbf{7}$ summarises the key economic indicators for each technology and thus conclusion on which is the most economically viable process can be derived. The HP technology clearly beats the competition as it benefits from higher fuel productivities. The latter factor is not sufficient for the G+FT to outplay the ZC. This is due to the higher capital investment costs and lower revenue derived from the by-products as the ZC is favoured from selling larger amounts of electricity. Therefore, it can be seen that it is always crucial to examine technical and economic indicators hand in hand and identify possible trade-offs.

\section{(Figure 7 here)}


Table 7. Summary of the economic results for each case

\begin{tabular}{|c|c|c|c|}
\hline & HP & G+FT & ZC \\
\hline MJSP (\$/L) & 1.98 & 2.32 & 2.21 \\
\hline PEC (M\$) & 150 & 152 & 132 \\
\hline TCl (M\$) & 1085 & 1095 & 950 \\
\hline $\mathrm{ACC}^{*}(\mathrm{M} \$ / \mathrm{y})$ & 119 & 120 & 104 \\
\hline OPEX (M\$/y) & 147 & 148 & 150 \\
\hline Revenue from by-products ( $M \$ / y)$ & 81.4 & 71.6 & 75.2 \\
\hline ACC per kg of jet fuel (\$/kg) & 1.52 & 1.69 & 1.54 \\
\hline OPEX per kg of jet fuel (\$/kg) & 1.87 & 2.1 & 2.21 \\
\hline Jet fuel production cost** $(\$ / \mathrm{kg})$ & 3.39 & 3.79 & 3.75 \\
\hline Overall fuel production cost $* *(\$ / \mathrm{kg})$ & 1.69 & 1.89 & 1.88 \\
\hline \multicolumn{4}{|c|}{$\begin{array}{l}* A C C \text { is the annualised capital cost }=T C I \times \frac{W A C C \times(1+W A C C)^{n}}{-1+(1+W A C C)^{n}} \\
* * \text { Production cost }=(A C C+O P E X) / \text { annual fuel (overall or jet) production; does not include revenue } \\
\text { from by-products }\end{array}$} \\
\hline
\end{tabular}

\section{Interpretation}

\subsection{Sensitivity analysis}

A local sensitivity analysis (LSA) was conducted by varying one independent parameter to its min or max value and retaining all the rest at their nominal values. Then, the discrepancy between the MJSP, when the variable is set to its min and to its max value, was estimated. Sensitivity analysis is a financial instrument intended to detect the factors responsible for significant cost deviations. In principle, the capital expenditures estimates possess an uncertainty of $\pm 30 \%$ (81) and in order to account for market volatilities a $\pm 20 \%$ range was assigned for raw material prices. For electricity prices the lower and the upper bounds were fixed to $0.04 \$ / \mathrm{kWh}$ and $0.1 \$ / \mathrm{kWh}$ respectively. Finally, the upper value for the bio-oil yield is $70 \%$ (feedstock dry basis) while the lower limit was taken as $50 \%$.

As depicted in Figure 8, the assessment revealed that all processes are primarily capital intensive as well as highly sensitive to bio-oil yield - the higher the yield the lower the MJSP. The latter indicates that improving the technical performance of the pyrolysis unit should be an early priority. Achieving accuracy in capital cost estimation is a major challenge at the early-stage of project definition and significant uncertainty reduction can only be attained via obtaining capital cost data from a commercial biomass to liquids plant which is not presently available. Furthermore, changes in feedstock prices represent a significant source of uncertainty; to diminish volatilities in the feedstock price, the agreement of a longstanding biomass procurement deal with determined quantities and 
charges should be pursued with an agricultural or forest management corporation (82). The raw material expenditures (catalysts, methane, oxygen etc.) and the electricity prices have a slightly greater effect on the $\mathrm{ZC}$ route due to the high price of zeolite catalyst and the increased power generation. In addition, the estimate for the MJSP of the most optimistic scenario can be calculated from the accumulated effect of the variable changes. Under these positive circumstances, the MJSP reduces to $0.76 \$ / L, 1.1 \$ / L$ and $0.93 \$ / L$ for the HP, G+FT and ZC pathways respectively. These values come close to the conventional jet fuel but even so, as it will be discussed in the next section, the probability of such an occurrence should be considered negligible.

\section{(Figure 8 here)}

\subsection{Stochastic uncertainty analysis}

A constraint of LSA is that ambiguous parameters are usually investigated individually while the rest of the variables remain fixed. Hence, possible exchanges that may occur among the variables may be ignored. It is common that the values of numerous variables to be altered at the same time, for instance, as a bounding assessment with variables arranged to their maximum or minimum values. Nevertheless, LSA cannot provide any evidence on the probability of such extreme occurrences. A more robust method is an examination based on probabilistic criteria wherein distribution functions are allocated to several independent parameters. The sample of the distributions takes place in a repetitive manner by means of Monte Carlo (or related) simulations to generate a distribution function that displays the likelihood of a determined upshot to occur.

After identifying the dominant parameters, i.e. CAPEX, bio-oil yield and feedstock price, a Monte Carlo simulation (the code was developed in Matlab environment) was applied to characterise the influence of uncertainty or variability of these factors on MJSP. Triangular distributions were assigned to the parameters as with such distributions the results tend toward the normal or log-normal distributions (preferred by purists) and are suitable for the present problem (minimum, maximum, and most likely values are required). The MJSP for each case was calculated for random combination of these variables considering 10,000 iterations. Figure 9 depicts the cumulative probability functions for the proposed biorefineries. The steepness of the HP curve suggests a smaller value of variance compared to the other cases and narrower ranges of confidence interval; thus less uncertainty. The desired level of confidence is set by the researcher but most commonly, the $95 \%$ confidence level is used. Therefore, the HP alternative possess a 95\% probability that the MJSP will lie between $1.6-2.38 \$ / L$, the G+FT is in the range of 1.8-2.85 $\$ / L$ and the $Z C$ varies from 1.7 to $2.75 \$ / L$. As reported in (83), awareness of 
the probability distributions related to economic indicators are "particularly important for determining near term optimal technology policy" and that, in the context of climate change, such information is able to influence and support policy makers' decisions and promote substantially greater levels of R\&D investment.

\section{(Figure 9 here)}

\subsection{Effect of the plant size}

In principle, the selection of a biorefinery capacity comprises trade-offs between benefits gained from the economies of scale of bigger facilities and augmented costs of biomass. The delivery fee for a unit of feedstock rises as the size of the biorefinery escalates for the reason that the feedstock has to be delivered from gradually longer distances (84). As such, a scaling factor, $f$, greater than 1 and equal to 1.5 has been suggested (84) to account for this trend observed in biomass transportation costs. Assuming that transportation costs account for $20 \%$ of the feedstock price, the remaining share was scaled up considering a linear relationship with size $(f=1)$. In addition, the scaling factors presented in Figure 4 were utilised for the CAPEX.

Figure 10 provides the effect of economies of scale on the MJSPs for all cases. As anticipated, the prices initially fall swiftly, since the CAPEX is the prime cost driver, until they reach a minimum value. After these values, feedstock costs take over and the negative effect of transportation costs cause prices to increase. For all scenarios, it was observed that the optimum size of the plant is around 150 $\mathrm{dt} / \mathrm{h}$. At this capacity the MJSPs are $1.49 \$ / \mathrm{L}, 1.75 \$ / L$ and $1.66 \$ / L$ for the HP, G+FT and ZC respectively. On the other hand for sizes lower than $50 \mathrm{dt} / \mathrm{h}$ the biojet fuel price can be more than ten times higher than the fossil fuel price, signifying that the implementation of the proposed biorefineries cannot be competitive at low scales and the ideal scale should lie between 100 and $150 \mathrm{dt} / \mathrm{h}$ of biomass feedstock.

\section{(Figure 10 here)}

\subsection{Policy scenario}

The effect of policy on the examined biorefineries viability is carried out in this section by evaluating the Second Generation Biofuel Producer Tax Credit (SGBPTC) and the Renewable Identification Number (RIN) scheme. Even if establishing policies related to mitigating emissions in the aviation sector is still challenging and a global issue mainly due to the lack of a standardised methodology that will effectively apportion emissions between countries and/or regions (85), the investigated policy 
schemes, in this study, are existing mechanisms aiming to reward local producers that introduce to the market low carbon fuels.

The SGBPTC incentive was originally expired on December 31, 2016, but it was retroactively extended through December 31, 2017; in this study it is assumed that it will be effective throughout the whole lifetime of the projects. The SGBPTC law diminishes the producer's income tax liability by $\$ 0.267$ for every litre of cellulosic biofuel manufacture for use in the United States (86). The impact of the incentive on the NPV was investigated for each case study in a two-way fashion for calculating the biojet fuel revenue flows: first by considering the computed MJSP and secondly the market price. As depicted in Figure 11, the implementation of SGBPTC generates positive NPVs for all cases when the respective MJSPs are considered. Nevertheless, the establishment of such high selling prices for biofuels should be measured an unrealistic scenario. On the other hand, when biojet fuel is sold on the market price huge losses are reported, from 350 to $485 \mathrm{M} \$$. In the latter case, the tax credit has no effect during the first half of the projects' lifetime (10 years) as the earnings before interest and tax (EBIT) are negative and thereby there is no taxable income; this in turn has a detrimental impact on the project profitability and leads to default. Therefore, this investigation incorporates, also, the effect of D3 (Cellulosic biofuels) RINs on the viability of the ventures. A RIN is a credit that is generated each time a gallon of renewable fuel is produced. The two are not inextricably linked, however, as the RIN can be split from the gallon when it is bought on the open market. The credit alone can then be sold to businesses interested in purchasing of RIN credits. Access to D3 RIN prices is not possible because of the low market volume of cellulosic biofuels. To overcome this issue, the methodology suggested by Stock (87) was adopted for calculating D3 RIN prices. According to this approach, D3 prices can be derived from the sum of the D5 (advanced biofuel) RIN price and the Cellulosic Waiver Credit (CWC). D5 RIN prices are typically volatile, however in this study a moderate and constant price of $\$ 1.04$ (88) was considered throughout the lifetime of the projects. In turn, the CWC is taken as $\$ 1.33$ (89). The event of combining SGBPTC and RINs is demonstrated in Figure 11. Based on the assumption that they both reflect existing conditions, this synergy can yield positive returns for all cases. In general, large-scale biorefineries will come at high investment costs and promotion of such ventures should focus on enhancing incomes, administering tax allowances and increasing the market value of biofuels.

\section{(Figure 11 here)}

\section{Concluding remarks}

The present research provides a holistic approach on assessing the economic viability of aviation biofuel routes based on biomass fast pyrolysis. In order to achieve consistency, it takes into account 
technical and economic criteria in weighing the performance of each process. Simulations were carried out in Aspen Plus environment aiming to establish and quantify mass and energy flows. The simulations set the basis for a detailed cost breakdown of the examined biojet fuel routes and subsequently, a net present value break-even assessment was used to estimate the minimum jet fuel price. The investigated alternatives focus on the upgrading section of bio-oil. These comprise hydroprocessing, gasification followed by Fischer Tropsch synthesis and zeolite cracking.

Based on a plant size of $100 \mathrm{dt} / \mathrm{h}$ of forest residues, it was concluded that hydroprocessing provides more advantages than the competitors. Given the process design described earlier, the HP route achieves the higher hydrocarbons mass efficiency, $19.58 \%$, followed by the G+FT, $17.72 \%$, and the ZC pathways, $16.96 \%$. The same trend was observed for the jet fuel mass efficiency and the achieved values are $9.79 \%(\mathrm{HP}), 8.68 \%(\mathrm{G}+\mathrm{FT})$ and $8.14 \%(\mathrm{ZC})$. The G+FT concept suffers from the numerous process steps incorporated in the production line while the ZC wastes carbon atoms as it rejects the oxygen content of the bio-oil in the form of $\mathrm{CO}_{2}$ as well as due to increased coke deposition.

The execution of a common discounted cash flow analysis led to MJSPs of $1.98,2.32$ and $2.21 \$ / L$ for the HP, G+FT and ZC respectively. Sensitivity analysis revealed that all processes are mainly capital intensive. Other crucial factors include bio-oil yield and feedstock price. Furthermore, the conduction of a stochastic Monte Carlo analysis suggests that the HP carries marginally less risk and there is a 95\% confidence interval that the MJSP will vary roughly $\pm 20 \%$ from the deterministic value compared to $\pm 22 \%$ and $\pm 24 \%$ for the G+FT and the ZC respectively. Based on a typical plant size analysis, it was observed that the ideal plant capacity for all cases is $150 \mathrm{dt} / \mathrm{h}$ of feedstock; above this threshold the economies of scale have a negative effect on the production costs due to increased biomass transportation costs.

The realisation of positive economic return is impossible under the existing techno-economic status. However, there are a number of technology, policy and market advances that can substantially enhance the economics of the investigated procedures. Establishing tax allowances (e.g. SGBPTC) and/or promoting policy scenarios (e.g. RINs) that will provide additional income can make the proposed lignocellulosic biorefineries profitable and attractive to potential investors.

Finally, the decision to implement new technologies usually takes into account all three, technological, economic and environmental criteria. Therefore, future research focusing on the life cycle assessment of the examined conversion routes is strongly recommended. 


\section{Acknowledgments}

This work was supported and funded by the Engineering and Physical Sciences Research Council as part of the Supergen Bioenergy Consortium. Their contribution is gratefully acknowledged by the authors.

\section{References}

1. Liu G, Yan B, Chen G. Technical review on jet fuel production. Renew Sustain Energy Rev [Internet]. Elsevier; 2013;25:59-70. Available from: http://dx.doi.org/10.1016/j.rser.2013.03.025

2. Statista. Commercial airlines worldwide - fuel consumption 2005-2019 [Internet]. Available from: https://www.statista.com/statistics/655057/fuel-consumption-of-airlines-worldwide/

3. Kandaramath Hari T, Yaakob Z, Binitha NN. Aviation biofuel from renewable resources: Routes, opportunities and challenges. Renew Sustain Energy Rev [Internet]. Elsevier; 2015;42:1234-44. Available from: http://dx.doi.org/10.1016/j.rser.2014.10.095

4. Gegg P, Budd L, Ison S. The market development of aviation biofuel: Drivers and constraints. J Air Transp Manag [Internet]. Elsevier Ltd; 2014;39:34-40. Available from: http://dx.doi.org/10.1016/j.jairtraman.2014.03.003

5. Capaz RS, Seabra JEA. Chapter 12 - Life Cycle Assessment of Biojet Fuels. In: Chuck CJ, editor. Biofuels for Aviation [Internet]. Academic Press; 2016. p. 279-94. Available from: http://www.sciencedirect.com/science/article/pii/B9780128045688000123

6. Deane JP, Pye S. Europe's ambition for biofuels in aviation - A strategic review of challenges and opportunities. Energy Strateg Rev [Internet]. 2018;20:1-5. Available from: http://www.sciencedirect.com/science/article/pii/S2211467X1730086X

7. Mawhood R, Gazis E, Jong S De, Hoefnagels R, Slade R. Production pathways for renewable jet fuel: a review of commercialization. Biofuels, Bioprod Bioref. 2016;

8. European Union Aviation Safety Agency. Sustainable Aviation Fuels [Internet]. Available from: https://www.easa.europa.eu/eaer/climate-change/sustainable-aviation-fuels\#8

9. Airport technology. Renewable jet fuels: how to handle the heavy costs [Internet]. 2018. Available from: https://www.airport-technology.com/features/renewable-jet-fuels-how-to-handle-the-heavycosts/

10. Wang WC, Tao L. Bio-jet fuel conversion technologies. Renew Sustain Energy Rev [Internet]. Elsevier; 2016;53:801-22. Available from: http://dx.doi.org/10.1016/j.rser.2015.09.016

11. Gutiérrez-Antonio C, Gómez-Castro FI, de Lira-Flores JA, Hernández S. A review on the production processes of renewable jet fuel. Renew Sustain Energy Rev [Internet]. Elsevier Ltd; 2017;79(October 2016):709-29. Available from: http://dx.doi.org/10.1016/j.rser.2017.05.108

12. Bridgwater A V. Renewable fuels and chemicals by thermal processing of biomass. Chem Eng J. 2003;91(2-3):87-102.

13. Bridgwater A V, Meier D, Radlein D. Fast pyrolysis of biomass:: a handbook. [Vol. 1]: [...]. 2008;30:188.

14. Bridgwater A V. Upgrading Biomass Fast Pyrolysis Liquids. Upgrad Biomass Fast Pyrolysis Liq. 2012;31(2):261-8.

15. Chiaramonti D, Prussi M, Buffi M, Tacconi D. Sustainable bio kerosene: Process routes and industrial demonstration activities in aviation biofuels. Appl Energy [Internet]. Elsevier Ltd; 2014;136:767-74. Available from: http://dx.doi.org/10.1016/j.apenergy.2014.08.065

16. Wang WC. Techno-economic analysis of a bio-refinery process for producing Hydro-processed Renewable Jet fuel from Jatropha. Renew Energy [Internet]. Elsevier Ltd; 2016;95:63-73. Available from: http://dx.doi.org/10.1016/j.renene.2016.03.107

17. Tan ECD, Snowden-Swan LJ, Talmadge M, Dutta A, Jones S, Ramasamy KK, et al. Comparative technoeconomic analysis and process design for indirect liquefaction pathways to distillate-range fuels via biomass-derived oxygenated intermediates upgrading. Biofuels, Bioprod Biorefining [Internet]. 2017;11(1):41-66. Available from: https://onlinelibrary.wiley.com/doi/abs/10.1002/bbb.1710

18. Klein-Marcuschamer D, Turner C, Allen M, Gray P, Dietzgen RG, Gresshoff PM, et al. Technoeconomic analysis of renewable aviation fuel from microalgae, Pongamia pinnata, and sugarcane. Biofuels, Bioprod Biorefining [Internet]. 2013;7(4):416-28. Available from: https://onlinelibrary.wiley.com/doi/abs/10.1002/bbb.1404

19. Atsonios K, Kougioumtzis M-A, Panopoulos KD, Kakaras E. Alternative thermochemical routes for 
aviation biofuels via alcohols synthesis: Process modeling, techno-economic assessment and comparison. Appl Energy [Internet]. 2015;138:346-66. Available from:

http://www.sciencedirect.com/science/article/pii/S0306261914011064

20. Pearlson M, Wollersheim C, Hileman J. A techno-economic review of hydroprocessed renewable esters and fatty acids for jet fuel production. Biofuels, Bioprod Biorefining [Internet]. 2013;7(1):89-96.

Available from: https://onlinelibrary.wiley.com/doi/abs/10.1002/bbb.1378

21. Diederichs GW, Mandegari MA, Farzad S, Görgens JF. Techno-economic comparison of biojet fuel production from lignocellulose, vegetable oil and sugar cane juice. Bioresour Technol [Internet]. 2016;216:331-9. Available from:

http://www.sciencedirect.com/science/article/pii/S0960852416307313

22. Li X, Mupondwa E, Tabil L. Technoeconomic analysis of biojet fuel production from camelina at commercial scale: Case of Canadian Prairies. Bioresour Technol [Internet]. 2018;249:196-205. Available from: http://www.sciencedirect.com/science/article/pii/S0960852417317595

23. Bann SJ, Malina R, Staples MD, Suresh P, Pearlson M, Tyner WE, et al. The costs of production of alternative jet fuel: A harmonized stochastic assessment. Bioresour Technol [Internet]. 2017;227:17987. Available from: http://www.sciencedirect.com/science/article/pii/S0960852416316911

24. Yao G, Staples MD, Malina R, Tyner WE. Stochastic techno-economic analysis of alcohol-to-jet fuel production. Biotechnol Biofuels [Internet]. 2017 Jan;10(1):18. Available from:

https://doi.org/10.1186/s13068-017-0702-7

25. Santos $\mathrm{Cl}$, Silva CC, Mussatto SI, Osseweijer P, van der Wielen LAM, Posada JA. Integrated 1st and 2nd generation sugarcane bio-refinery for jet fuel production in Brazil: Techno-economic and greenhouse gas emissions assessment. Renew Energy [Internet]. 2018;129:733-47. Available from:

http://www.sciencedirect.com/science/article/pii/S0960148117303968

26. Yang Z, Qian K, Zhang X, Lei H, Xin C, Zhang Y, et al. Process design and economics for the conversion of lignocellulosic biomass into jet fuel range cycloalkanes. Energy [Internet]. 2018;154:289-97. Available from: http://www.sciencedirect.com/science/article/pii/S0360544218307424

27. Sikanen L. First Commercial Pyrolysis Oil Plant in Finland - Technology, Value Network and SocioEconomic Effects [Internet]. 2016. Available from: https://www.cif-ifc.org/wpcontent/uploads/2016/10/First-Commercial-Pyrolysis-Oil-Plant-_-DEMO-2016_-Sikanen.pdf

28. Kozlo A, Tambuyser B, Vis M, Vis M. Virtual pyrolysis plant locations in Europe. Availability and quality of biomass resources at four potential sites [Internet]. 2018. Available from:

https://bio4products.eu/knowledge-transfer/\#1480440559658-f077b8cf-8598

29. Ringer M, Putsche V, Scahill J. Large-Scale Pyrolysis Oil Production: A Technology Assessment and Economic Analysis. 2006.

30. Michailos S, Parker D, Webb C. A multicriteria comparison of utilizing sugar cane bagasse for methanol to gasoline and butanol production. Biomass and Bioenergy [Internet]. 2016;95:436-48. Available from: http://www.sciencedirect.com/science/article/pii/S0961953416302215

31. Carrasco JL, Gunukula S, Boateng AA, Mullen CA, DeSisto WJ, Wheeler MC. Pyrolysis of forest residues: An approach to techno-economics for bio-fuel production. Fuel [Internet]. 2017;193:477-84. Available from: http://www.sciencedirect.com/science/article/pii/S0016236116312947

32. Das KC, Singh K, Bibens B, Hilten R, Baker SA, Greene W, et al. Pyrolysis Characteristics of Forest Residues Obtained from Different Harvesting Methods. Appl Eng Agric. 2010;27:107-13.

33. Batchfrac R. Aspen Physical Property. 2001;

34. AspenPlus. Aspen Plus 2004.1: Getting Started Modeling Processes with Solids. 2004;

35. Dutta A, Schaidle JA, Humbird D, Baddour FG, Sahir A. Conceptual Process Design and TechnoEconomic Assessment of Ex Situ Catalytic Fast Pyrolysis of Biomass: A Fixed Bed Reactor Implementation Scenario for Future Feasibility. Top Catal [Internet]. 2016 Jan;59(1):2-18. Available from: https://doi.org/10.1007/s11244-015-0500-z

36. Jones S, Meyer P, Snowden-Swan L, Padmaperuma A, Tan E, Dutta A, et al. Process design and economics for the conversion of lignocellulosic biomass to hydrocarbon fuels: Fast pyrolysis and hydrotreating bio-oil pathway [Internet]. Energy. 2013. Available from:

http://www.pnnl.gov/main/publications/external/technical_reports/PNNL23053.pdf\%5Cnhttp://www.nrel.gov/docs/fy14osti/61178.pdf

37. Index mundi commodity prices [Internet]. Available from: http://www.indexmundi.com/commodities

38. Towler G, Sinnott R. Chapter 7 - Capital Cost Estimating. In: Towler G, Sinnott R, editors. Chemical Engineering Design (Second Edition) [Internet]. Second Edi. Boston: Butterworth-Heinemann; 2013. p. 307-54. Available from: http://www.sciencedirect.com/science/article/pii/B9780080966595000079 
39. Jones SB, Snowden-Swan LJ, Meyer P, Zacher A, Olarte M V, Wang H, et al. Fast Pyrolysis and Hydrotreating: 2014 State of Technology R \& D and Projections to 2017. 2017.

40. Shemfe M, Gu S, Fidalgo B. Techno-economic analysis of biofuel production via bio-oil zeolite upgrading: An evaluation of two catalyst regeneration systems. Biomass and Bioenergy [Internet]. 2017;98:182-93. Available from:

http://www.sciencedirect.com/science/article/pii/S0961953417300375

41. Sadhukhan J, Ng KS, Hernandez EM. Biorefineries and Chemical Processes: Design, Integration and Sustainability Analysis [Internet]. Wiley; 2014. Available from:

https://books.google.co.uk/books?id=sqw-BAAAQBAJ

42. Albrecht FG, König DH, Baucks N, Dietrich RU. A standardized methodology for the techno-economic evaluation of alternative fuels - A case study. Fuel [Internet]. Elsevier Ltd; 2017;194:511-26. Available from: http://dx.doi.org/10.1016/j.fuel.2016.12.003

43. Lauven L-P, Karschin I, Geldermann J. Simultaneously optimizing the capacity and configuration of biorefineries. Comput Ind Eng [Internet]. 2018;124:12-23. Available from:

http://www.sciencedirect.com/science/article/pii/S0360835218303292

44. Peters MS, Timmerhaus KD. Plant design and economics for chemical engineers. McGraw-Hil; 1991.

45. Michailos S, McCord S, Sick V, Stokes G, Styring P. Dimethyl ether synthesis via captured CO2 hydrogenation within the power to liquids concept: A techno-economic assessment. Energy Convers Manag [Internet]. Elsevier; 2019;184(January):262-76. Available from: https://doi.org/10.1016/j.enconman.2019.01.046

46. Towler G, Sinnott R. Chapter 9 - Economic Evaluation of Projects. In: Towler G, Sinnott R, editors. Chemical Engineering Design (Second Edition) [Internet]. Second Edi. Boston: Butterworth-Heinemann; 2013. p. 389-429. Available from:

http://www.sciencedirect.com/science/article/pii/B9780080966595000092

47. Caputo AC, Palumbo M, Pelagagge PM, Scacchia F. Economics of biomass energy utilization in combustion and gasification plants: effects of logistic variables. Biomass and Bioenergy [Internet]. 2005;28(1):35-51. Available from:

http://www.sciencedirect.com/science/article/pii/S0961953404001205

48. Okeke IJ, Mani S. Techno-economic assessment of biogas to liquid fuels conversion technology via Fischer-Tropsch synthesis. Biofuels, Bioprod Biorefining [Internet]. 2017;11(3):472-87. Available from: https://onlinelibrary.wiley.com/doi/abs/10.1002/bbb.1758

49. Brown TR, Zhang Y, Hu G, Brown RC. Techno-economic analysis of biobased chemicals production via integrated catalytic processing. Biofuels, Bioprod Biorefining [Internet]. 2012;6(1):73-87. Available from: https://onlinelibrary.wiley.com/doi/abs/10.1002/bbb.344

50. Michailos S, Parker D, Webb C. A techno-economic comparison of Fischer-Tropsch and fast pyrolysis as ways of utilizing sugar cane bagasse in transportation fuels production. Chem Eng Res Des [Internet]. 2017;118:206-14. Available from: http://www.sciencedirect.com/science/article/pii/S0263876217300023

51. Kourkoumpas DS, Papadimou E, Atsonios K, Karellas S, Grammelis P, Kakaras E. Implementation of the Power to Methanol concept by using $\mathrm{CO} 2$ from lignite power plants: Techno-economic investigation. Int J Hydrogen Energy [Internet]. 2016;41(38):16674-87. Available from: http://www.sciencedirect.com/science/article/pii/S0360319916301239

52. Couper JR. Process Engineering Economics. CRC Press; 2003. 71, 97-100 p.

53. Michailos S, Parker D, Webb C. Simulation Studies on Ethanol Production from Sugar Cane Residues. Ind Eng Chem Res [Internet]. 2016;55(18):5173-9. Available from:

https://doi.org/10.1021/acs.iecr.5b04500

54. Turton R. Analysis, Synthesis, and Design of Chemical Processes. Pearson Education, Inc; 2009.

55. Bureau of Labor Statistics [Internet]. Available from: https://www.bls.gov/

56. Towler G, Sinnott R. Chapter 8 - Estimating Revenues and Production Costs. In: Towler G, Sinnott R, editors. Chemical Engineering Design (Second Edition) [Internet]. Second Edi. Boston: ButterworthHeinemann; 2013. p. 355-87. Available from:

http://www.sciencedirect.com/science/article/pii/B9780080966595000080

57. KPMG Corporate tax rates table [Internet]. Available from: https://home.kpmg.com/xx/en/home/services/tax/tax-tools-and-resources/tax-ratesonline/corporate-tax-rates-table.html

58. Michailos S. Process design, economic evaluation and life cycle assessment of jet fuel production from sugar cane residue. Environ Prog Sustain Energy [Internet]. 2018;37(3):1227-35. Available from: 
https://onlinelibrary.wiley.com/doi/abs/10.1002/ep.12840

59. Li Q, Zhang Y, Hu G. Techno-economic analysis of advanced biofuel production based on bio-oil gasification. Bioresour Technol [Internet]. 2015;191:88-96. Available from:

http://www.sciencedirect.com/science/article/pii/\$0960852415006665

60. Andersson E, Harvey S, Berntsson T. Energy efficient upgrading of biofuel integrated with a pulp mill. Energy. 2006;31(10-11):1384-94.

61. Wright MM, Daugaard DE, Satrio JA, Brown RC. Techno-economic analysis of biomass fast pyrolysis to transportation fuels. Fuel. Elsevier Ltd; 2010;89(SUPPL. 1):S2-10.

62. Mellin P, Kantarelis E, Zhou C, Yang W. Simulation of Bed Dynamics and Primary Products from Fast Pyrolysis of Biomass: Steam Compared to Nitrogen as a Fluidizing Agent. Ind Eng Chem Res [Internet]. 2014;53(30):12129-42. Available from: https://doi.org/10.1021/ie501996v

63. Bridgwater A V, Peacocke GVC. Fast pyrolysis processes for biomass. Renew Sustain Energy Rev [Internet]. 2000;4(1):1-73. Available from:

http://www.sciencedirect.com/science/article/pii/S1364032199000076

64. Rogers JG, Brammer JG. Estimation of the production cost of fast pyrolysis bio-oil. Biomass and Bioenergy [Internet]. 2012;36:208-17. Available from:

http://www.sciencedirect.com/science/article/pii/S0961953411005435

65. Sarkar S, Kumar A. Large-scale biohydrogen production from bio-oil. Bioresour Technol [Internet]. 2010;101(19):7350-61. Available from:

http://www.sciencedirect.com/science/article/pii/\$0960852410007200

66. Swanson RM, Platon A, Satrio JA, Brown RC. Techno-economic analysis of biomass-to-liquids production based on gasification. Fuel [Internet]. 2010;89:S11-9. Available from:

http://www.sciencedirect.com/science/article/pii/S0016236110003741

67. Argyle MD, Bartholomew CH. Heterogeneous Catalyst Deactivation and Regeneration: A Review. Catalysts [Internet]. 2015;5(1):145-269. Available from: http://www.mdpi.com/2073-4344/5/1/145

68. Sudiro $M$, Bertucco A. Production of synthetic gasoline and diesel fuel by alternative processes using natural gas and coal: Process simulation and optimization. Energy [Internet]. 2009;34(12):2206-14.

Available from: http://www.sciencedirect.com/science/article/pii/\$0360544208003186

69. Knoef H. Handbook biomass gasification [Internet]. BTG Biomass Technology Group; 2012. Available from: https://books.google.co.uk/books?id=3q7CIAEACAAJ

70. Trippe F, Fröhling M, Schultmann F, Stahl R, Henrich E. Techno-economic assessment of gasification as a process step within biomass-to-liquid (BtL) fuel and chemicals production. Fuel Process Technol [Internet]. 2011;92(11):2169-84. Available from: http://www.sciencedirect.com/science/article/pii/S0378382011002463

71. Ng KS, Sadhukhan J. Process integration and economic analysis of bio-oil platform for the production of methanol and combined heat and power. Biomass and Bioenergy [Internet]. 2011;35(3):1153-69.

Available from: http://www.sciencedirect.com/science/article/pii/\$0961953410004320

72. Michailos S, Parker D, Webb C. Design, Sustainability Analysis and Multiobjective Optimisation of Ethanol Production via Syngas Fermentation. Waste and Biomass Valorization [Internet]. Springer Netherlands; 2017;0(0):1-12. Available from: http://dx.doi.org/10.1007/s12649-017-0151-3

73. Puig-Arnavat M, Bruno JC, Coronas A. Review and analysis of biomass gasification models. Renew Sustain Energy Rev [Internet]. Elsevier Ltd; 2010;14(9):2841-51. Available from:

http://dx.doi.org/10.1016/j.rser.2010.07.030

74. Boot-Handford ME, Abanades JC, Anthony EJ, Blunt MJ, Brandani S, Mac Dowell N, et al. Carbon capture and storage update. Energy Environ Sci [Internet]. The Royal Society of Chemistry; 2014;7(1):130-89. Available from: http://dx.doi.org/10.1039/C3EE42350F

75. Tock L, Gassner M, Maréchal F. Thermochemical production of liquid fuels from biomass: Thermoeconomic modeling, process design and process integration analysis. Biomass and Bioenergy [Internet]. 2010;34(12):1838-54. Available from: http://www.sciencedirect.com/science/article/pii/S0961953410002424

76. Schulz H, Claeys M. Reactions of $\alpha$-olefins of different chain length added during Fischer-Tropsch synthesis on a cobalt catalyst in a slurry reactor. Appl Catal A Gen [Internet]. 1999;186(1):71-90. Available from: http://www.sciencedirect.com/science/article/pii/\$0926860X99001659

77. Shi B, Davis BH. Fischer-Tropsch synthesis: The paraffin to olefin ratio as a function of carbon number. Catal Today [Internet]. 2005;106(1):129-31. Available from:

http://www.sciencedirect.com/science/article/pii/\$0920586105005092

78. Sharma RK, Bakhshi NN. Catalytic upgrading of fast pyrolysis oil over hzsm-5. Can J Chem Eng 
[Internet]. 1993;71(3):383-91. Available from:

https://onlinelibrary.wiley.com/doi/abs/10.1002/cjce.5450710307

79. Adjaye JD, Katikaneni SPR, Bakhshi NN. Catalytic conversion of a biofuel to hydrocarbons: effect of mixtures of HZSM- 5 and silica-alumina catalysts on product distribution. Fuel Process Technol [Internet]. 1996;48(2):115-43. Available from:

http://www.sciencedirect.com/science/article/pii/S0378382096010314

80. Couper JR, Penney WR, Fair JR. Chemical Process Equipment - Selection and Design (Revised 2nd Edition) [Internet]. Elsevier Science; 2009. Available from:

https://books.google.co.uk/books?id=jlR12Zz2SfoC

81. P C, LR D, J B , D B, RC C, J. H. Cost estimate classification system-as applied in engineering, procurement, and construction for the process industries. 2016.

82. Dimitriou I, Goldingay H, Bridgwater A V. Techno-economic and uncertainty analysis of Biomass to Liquid (BTL) systems for transport fuel production. Renew Sustain Energy Rev [Internet]. Elsevier Ltd; 2018;88(March):160-75. Available from: https://doi.org/10.1016/j.rser.2018.02.023

83. Baker E, Shittu E. Uncertainty and endogenous technical change in climate policy models. Energy Econ. 2008;30(6):2817-28.

84. Wright M, Brown RC. Establishing the optimal sizes of different kinds of biorefineries. Biofuels, Bioprod Biorefining [Internet]. 2007;1(3):191-200. Available from:

https://onlinelibrary.wiley.com/doi/abs/10.1002/bbb.25

85. Wood FR, Bows A, Anderson K. Apportioning aviation $\mathrm{CO} 2$ emissions to regional administrations for monitoring and target setting. Transp Policy [Internet]. 2010;17(4):206-15. Available from:

http://www.sciencedirect.com/science/article/pii/S0967070X10000223

86. Brinkman MLJ, da Cunha MP, Heijnen S, Wicke B, Guilhoto JJM, Walter A, et al. Interregional assessment of socio-economic effects of sugarcane ethanol production in Brazil. Renew Sustain Energy Rev [Internet]. 2018;88:347-62. Available from:

http://www.sciencedirect.com/science/article/pii/S1364032118300340

87. Stock JH. Administering the Cellulosic Requirements under the Renewable Fuel Standard with Increasing and Uncertain Supply. 2015.

88. Brown TR. Price uncertainty, policy, and the economic feasibility of cellulosic biorefineries. Biofuels, Bioprod Biorefining [Internet]. 2018;12(3):485-96. Available from:

https://onlinelibrary.wiley.com/doi/abs/10.1002/bbb.1865

89. United States Environmental Protection Agency. Renewable Fuel Standard Program [Internet]. Available from: https://www.epa.gov/renewable-fuel-standard-program/notice-cellulosic-waivercredit-price-calculation-2016\#additional-resources 


\section{Appendix A - Data for economic evaluation}

Table A.1. Equipment cost data

\begin{tabular}{lcccccc}
\hline Process section & $\mathbf{C}_{\mathbf{0}}$ (M\$) & $\mathbf{S}_{\mathbf{0}}$ & Unit & $\mathbf{f}$ & Base year & Reference \\
\hline HP upgrading & 23 & 58.37 & $\mathrm{~m}^{3} / \mathrm{h}$ (oil input) & 0.65 & 2011 & $(39)$ \\
Zeolite cracking & 2.14 & 1.61 & $\mathrm{t} / \mathrm{h}$ (bio-oil feed) & 0.65 & 2013 & $(40)$ \\
Steam turbine & 5.1 & 10 & $\mathrm{MWe}$ & 0.8 & 2001 & $(41)$ \\
Biomass reception & 4.17 & 2000 & $\mathrm{dt} / \mathrm{d}$ & 0.8 & 2016 & $(42)$ \\
Burner & 2.4231 & 20 & $\mathrm{MW}$ (heat duty) & 0.83 & 2014 & $(42)$ \\
Compressor & 0.6027 & 413 & $\mathrm{~kW}$ (power & 0.68 & 2014 & $(42)$ \\
Cyclone & 0.0615 & 1 & $\mathrm{~m}^{3} / \mathrm{s}$ (total gas flow) & 0.7 & 2014 & $(42)$ \\
EF-gasifier & 127.4895 & 78 & $\mathrm{t} / \mathrm{h}$ (biomass input) & 0.7 & 2014 & $(42)$ \\
Fast pyrolysis & 7.3554 & 14.3 & $\mathrm{t} / \mathrm{h}$ (biomass input) & 0.7 & 2014 & $(42)$ \\
Gas/liquid separator & 0.1107 & 10 & $\mathrm{~m}$ (unit length) & 0.79 & 2014 & $(42)$ \\
FT reactor & 21.6726 & 208 & $\mathrm{~m}$ (reactor volume) & 1 & 2014 & $(42)$ \\
Heat exchanger & 0.3198 & 1000 & $\mathrm{~m}$ (surface area) & 1 & 2014 & $(42)$ \\
PSA & 7.2447 & 0.294 & $\mathrm{kmol} / \mathrm{s}$ (purge gas flow) & 0.74 & 2014 & $(42)$ \\
Pump & 0.123 & 10 & $\mathrm{~m} 3 / \mathrm{s}$ (liquid flow) & 0.36 & 2014 & $(42)$ \\
WGS reactor & 3.4194 & 150 & $\mathrm{~kg} / \mathrm{s}$ (total gas feed) & 0.67 & 2014 & $(42)$ \\
Reformer & 3.4194 & 150 & $\mathrm{~kg} / \mathrm{s}$ (total gas feed) & 0.67 & 2014 & $(42)$ \\
Wax cracker & 0.02616 & 1 & $\mathrm{t} / \mathrm{y}$ (fuel products) & 0.55 & 2015 & $(43)$ \\
Saturation reactor & 0.08175 & 1 & $\mathrm{t} / \mathrm{y}$ (fuel products) & 0.6 & 2015 & $(43)$ \\
Biomass drying & 0.024525 & 1 & $\mathrm{t} / \mathrm{y}$ (fuel products) & 0.77 & 2015 & $(43)$ \\
Product recovery & 0.00052647 & 1 & $\mathrm{t} / \mathrm{y}$ (fuel products) & 0.7 & 2015 & $(43)$ \\
Distillation columns & & & $\mathrm{Aspen}$ Process Economic Analyser & & \\
\hline
\end{tabular}


Table A.2. Total Capital Investment (TCI) estimation methodology (38)(44)(45)

\begin{tabular}{l|c}
\hline Cost component & Lang factor \\
\hline Purchased Equipment Cost (PEC) & 1 \\
Purchased Equipment Installation & 0.39 \\
Instrumentation and controls & 0.26 \\
Piping & 0.31 \\
Electrical Systems & 0.1 \\
Buildings(including services) & 0.29 \\
Yard Improvements & 0.12 \\
ISBL & $\mathbf{2 . 4 7}$ \\
\hline OSBL & $\mathbf{0 . 1 2 \times I S B L}$ \\
\hline Engineering and Supervision & $0.32 \times(\mathrm{ISBL}+\mathrm{OSBL})$ \\
Construction Expenses & $0.34 \times(\mathrm{ISBL}+\mathrm{OSBL})$ \\
Legal Expenses & $0.04 \times(\mathrm{ISBL}+\mathrm{OSBL})$ \\
Contractor's Fee & $0.19 \times(\mathrm{ISBL}+\mathrm{OSBL})$ \\
Indirect costs (IC) & $\mathbf{0 . 8 9 \times ( I S B L + O S B L )}$ \\
\hline Project Contingency & $0.15 \times(\mathrm{ISBL}+\mathrm{OSBL}+\mathrm{IC})$ \\
Process Contingency & $0.05 \times(\mathrm{ISBL}+\mathrm{OSBL}+\mathrm{IC})$ \\
\hline Fixed Capital Investment (FCI) & Contingencies + ISBL + OSBL+ IC \\
\hline Working Capital (WC) & $0.15 \times \mathrm{FCl}$ \\
\hline Total Capital Investment (TCI) & $\mathbf{F C l + W C}$ \\
\hline
\end{tabular}

Table A.3. Methodology for fixed costs (41)(52)(53)

\begin{tabular}{ll}
\hline Parameter & Price \\
\hline Supervision & $0.25 \times$ Labour \\
Direct overhead & $0.5 \times($ Labour + supervision $)$ \\
General overhead & $0.65 \times($ Labour + supervision + direct $)$ \\
Maintenance labour & $0.015 \times \mathrm{FCl}$ \\
Maintenance material & $0.015 \times \mathrm{FCl}$ \\
Insurance and tax & $0.02 \times \mathrm{FCl}$ \\
\hline${ }^{\mathrm{a}} M=$ Maintenance labour \& maintenance material \\
\hline
\end{tabular}


a

Pre-reformer Reformer WGS

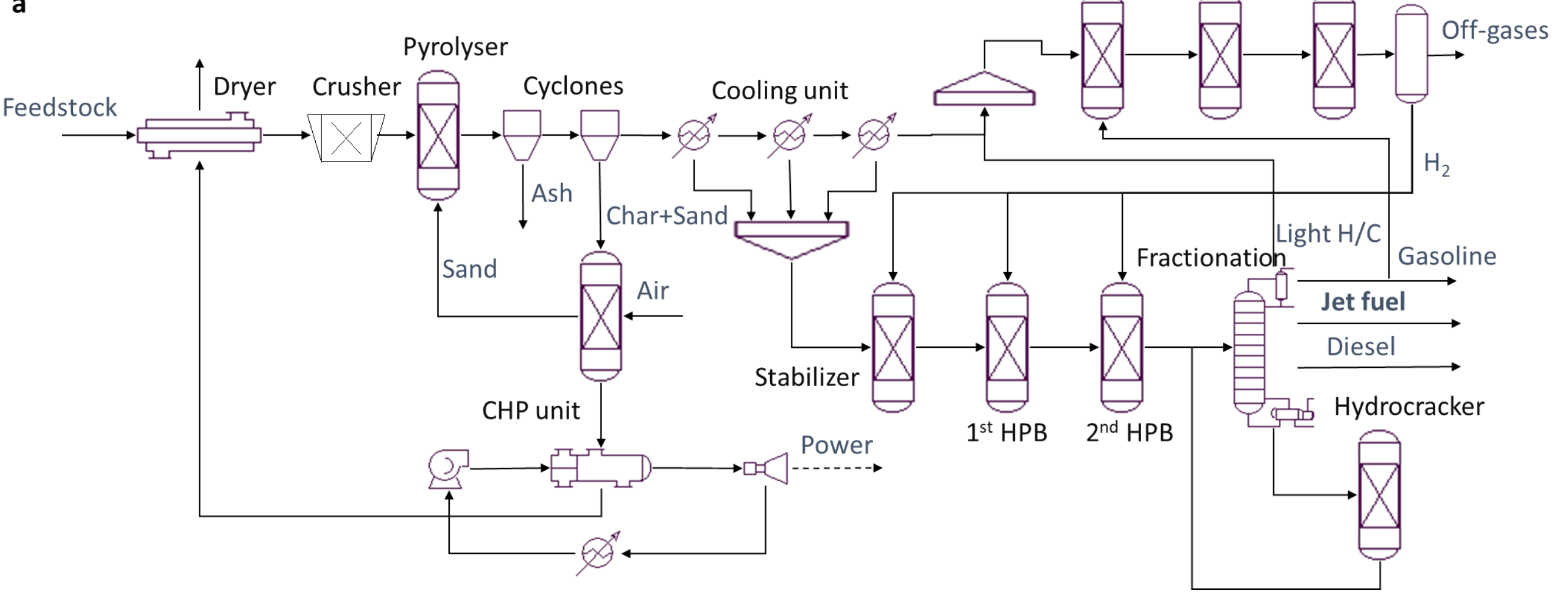




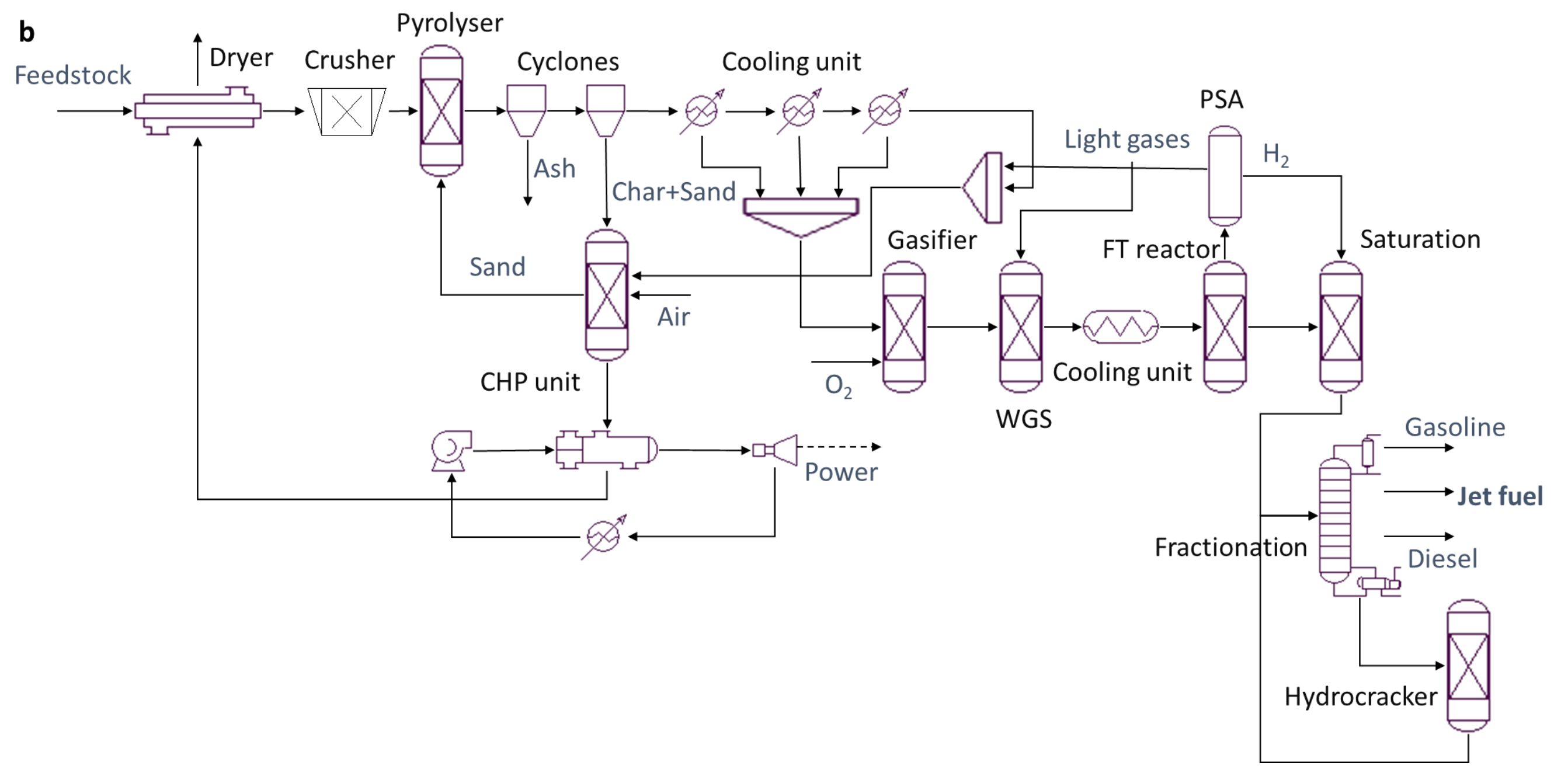




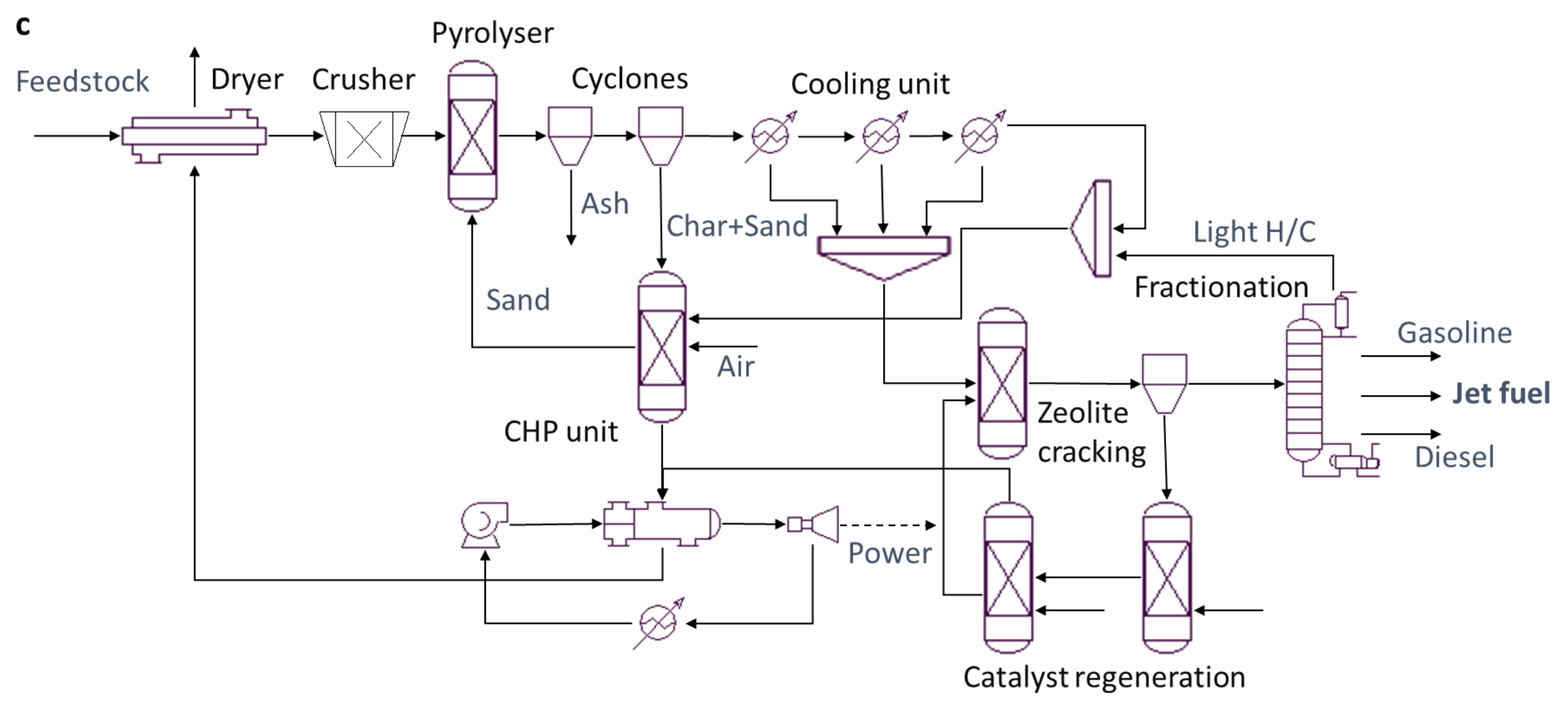

Figure 1. Simplified process flow diagrams for each case a) HP, b) G+FT and c) ZC. 


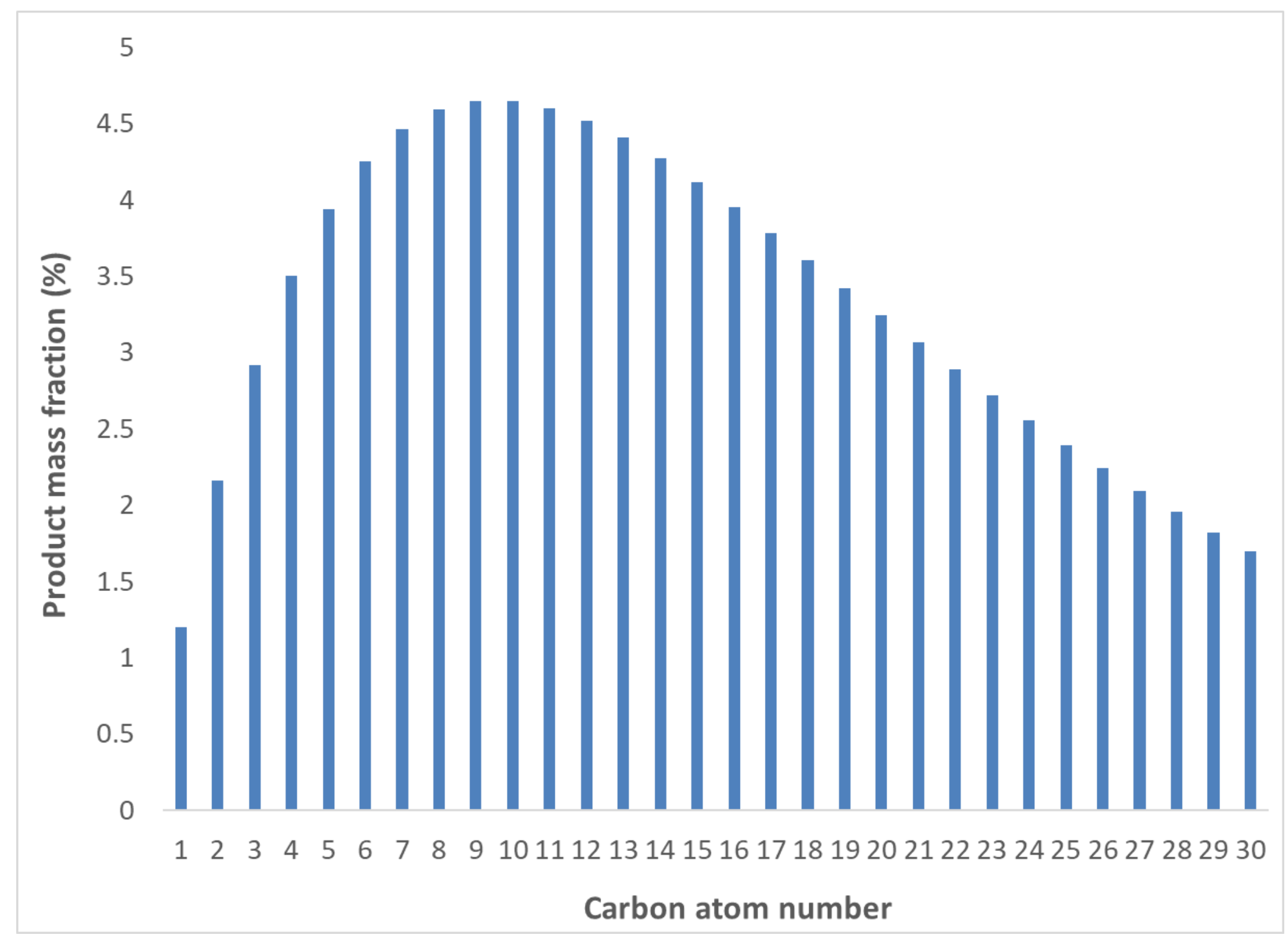

Figure 2. Fischer-Tropsch product distribution for $a=0.9$ 


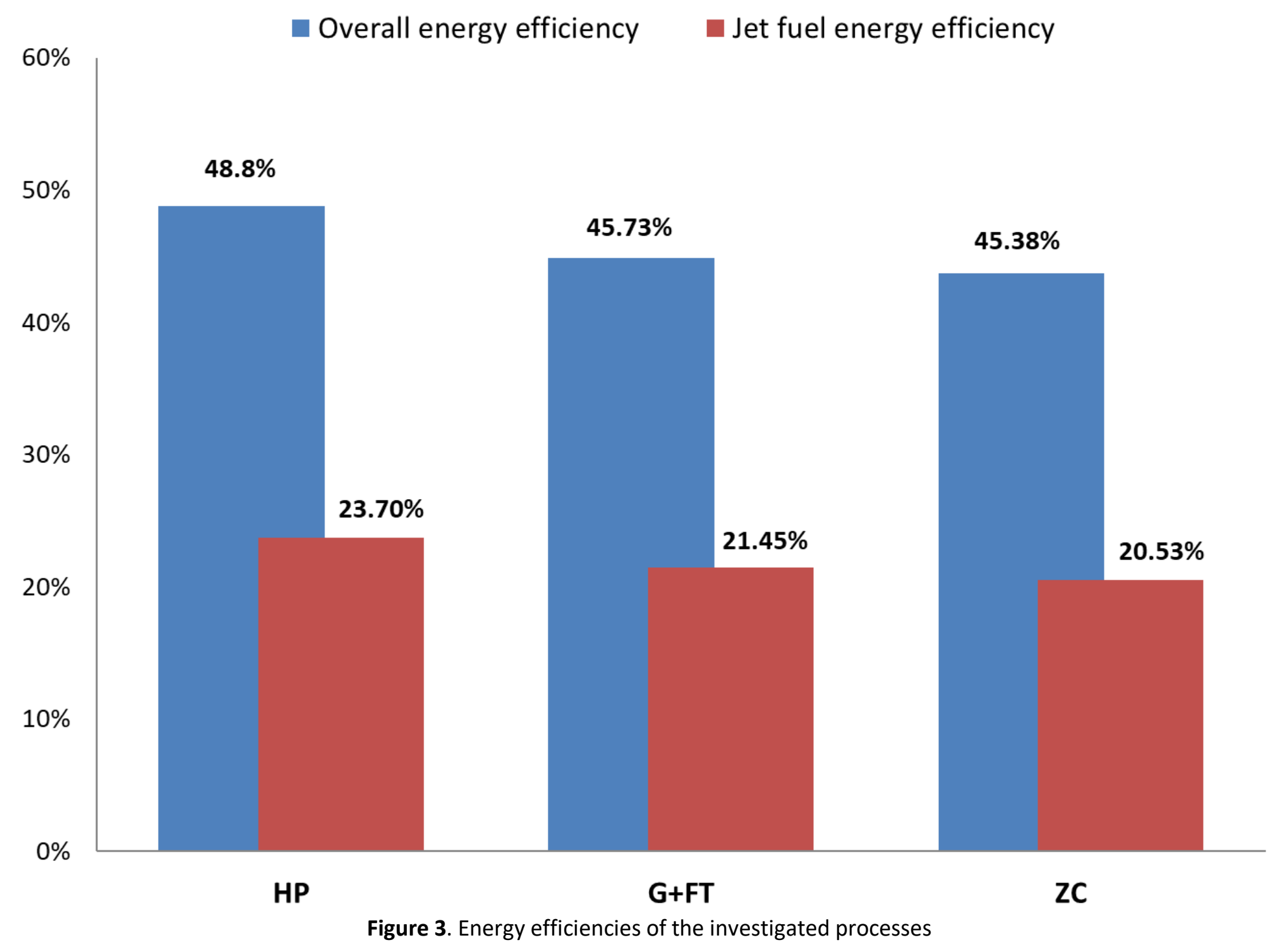




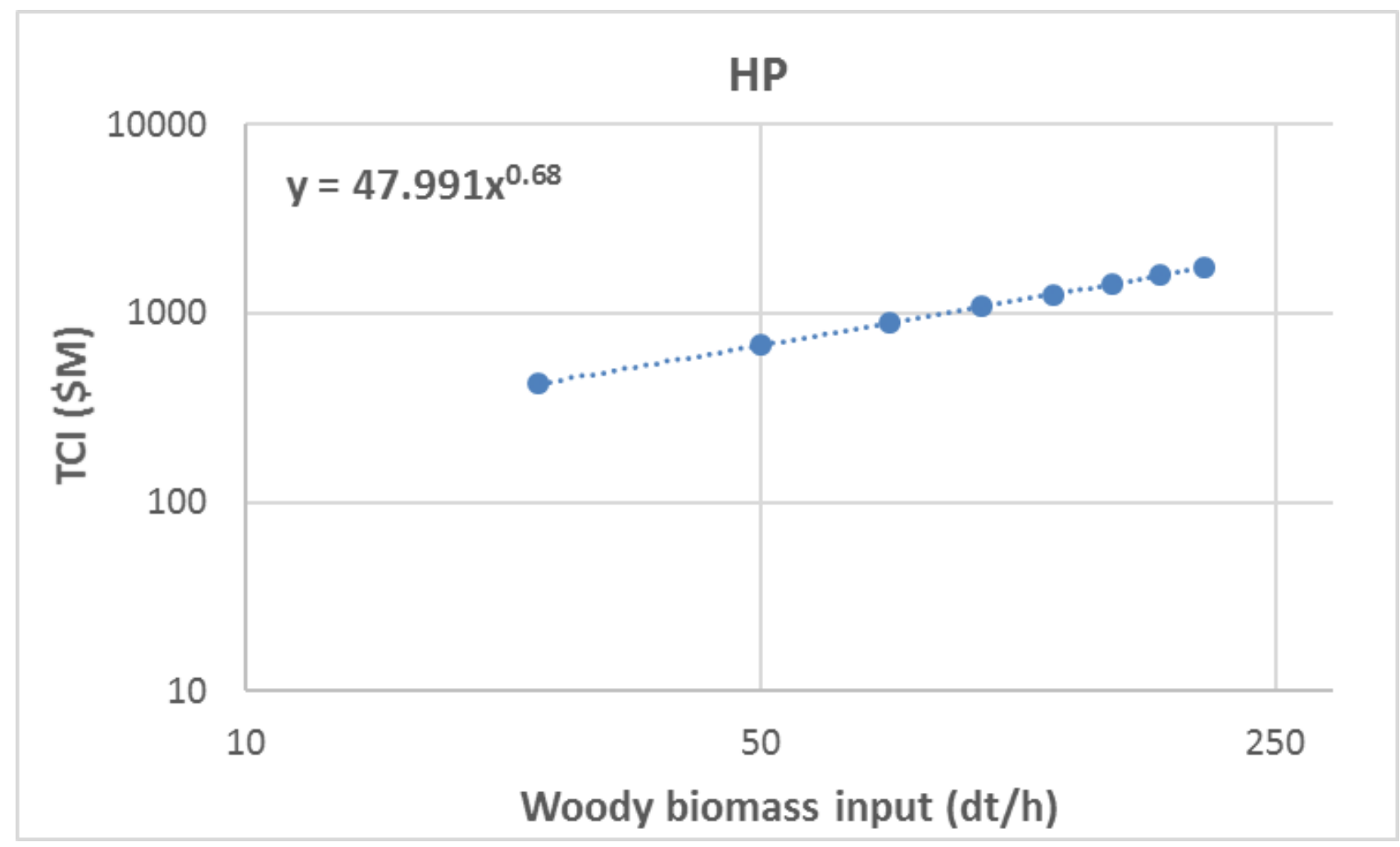




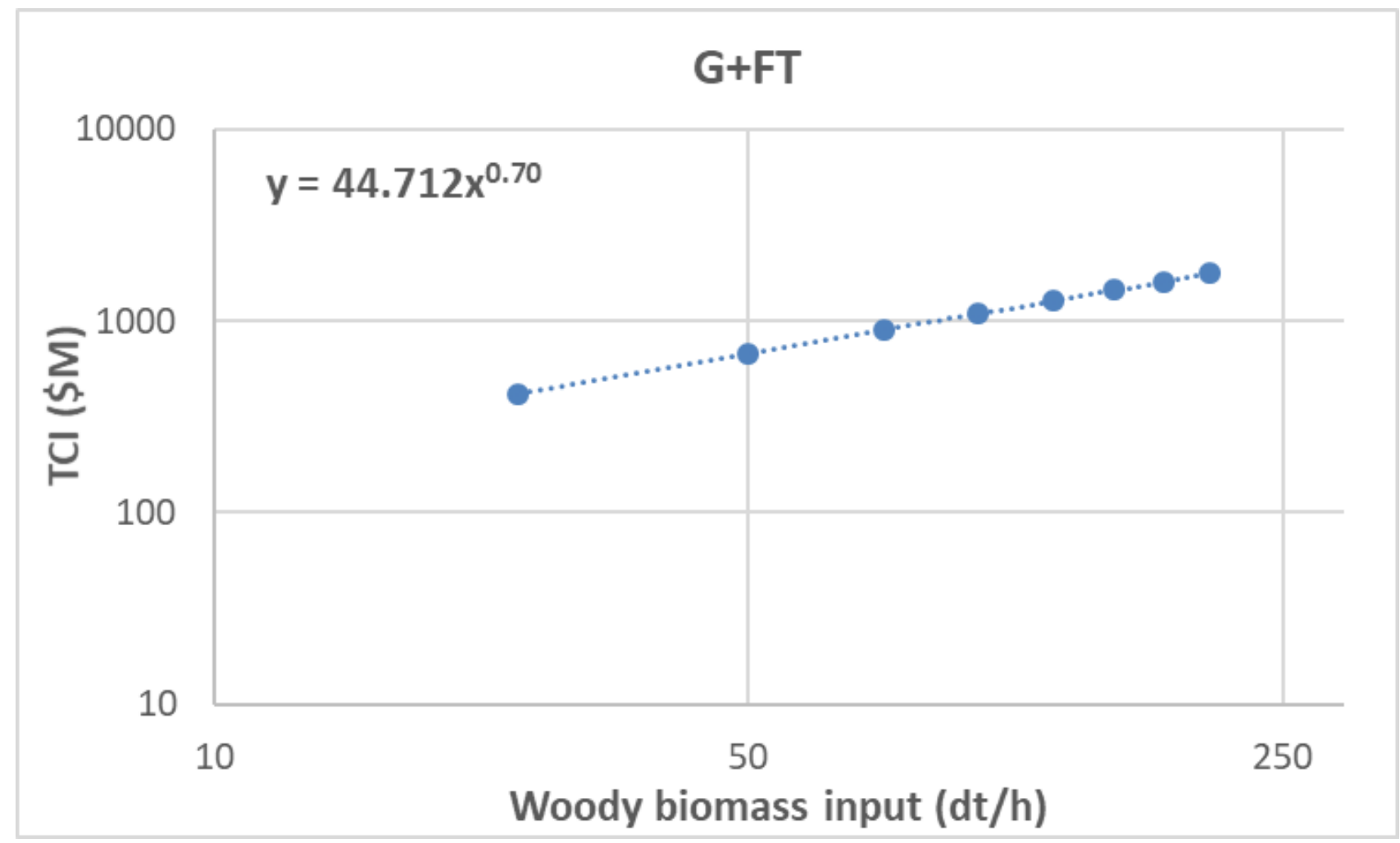




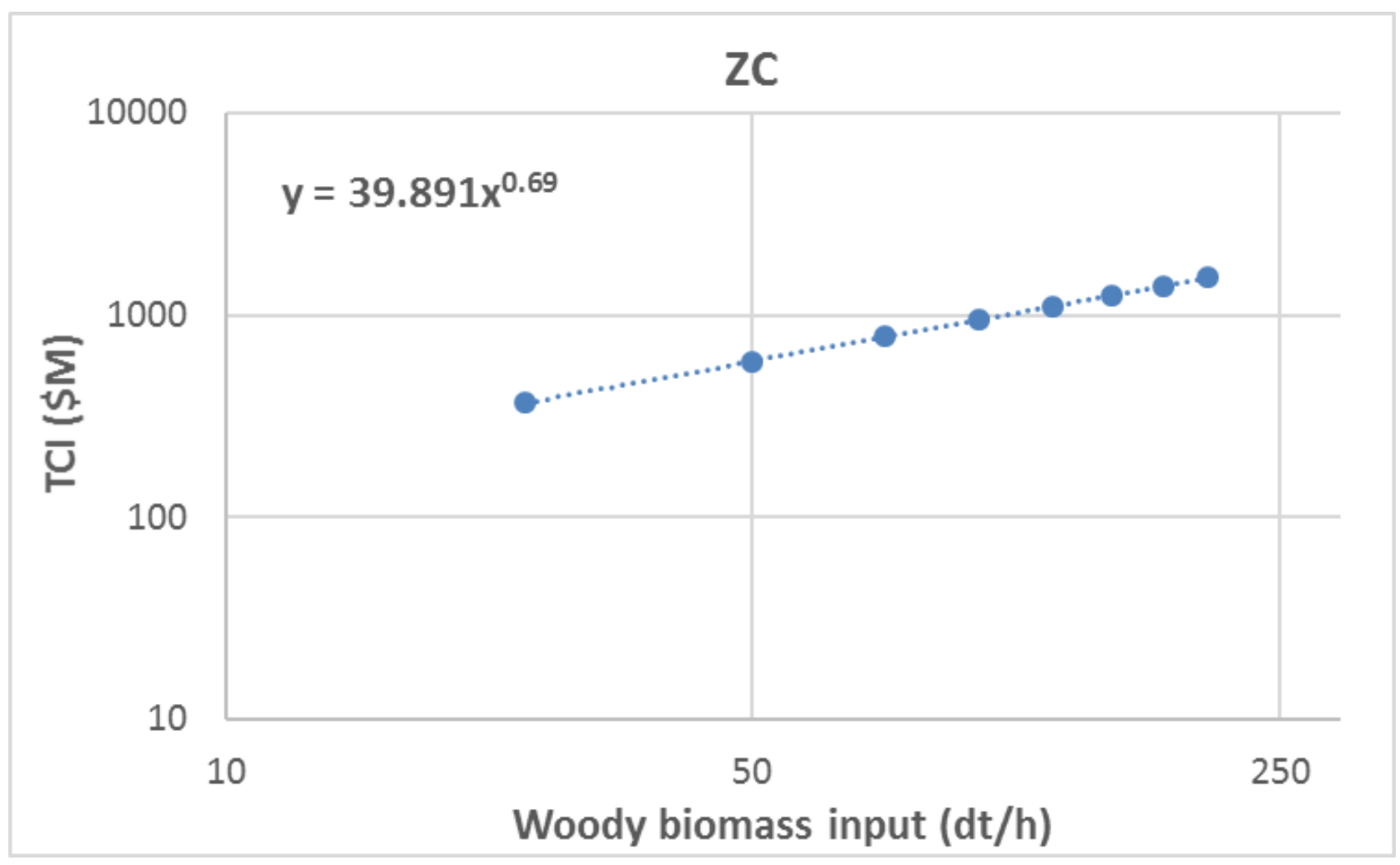

Figure 4. Calculated $\mathrm{TCl}$ scaling factors for the proposed biorefinery schemes 


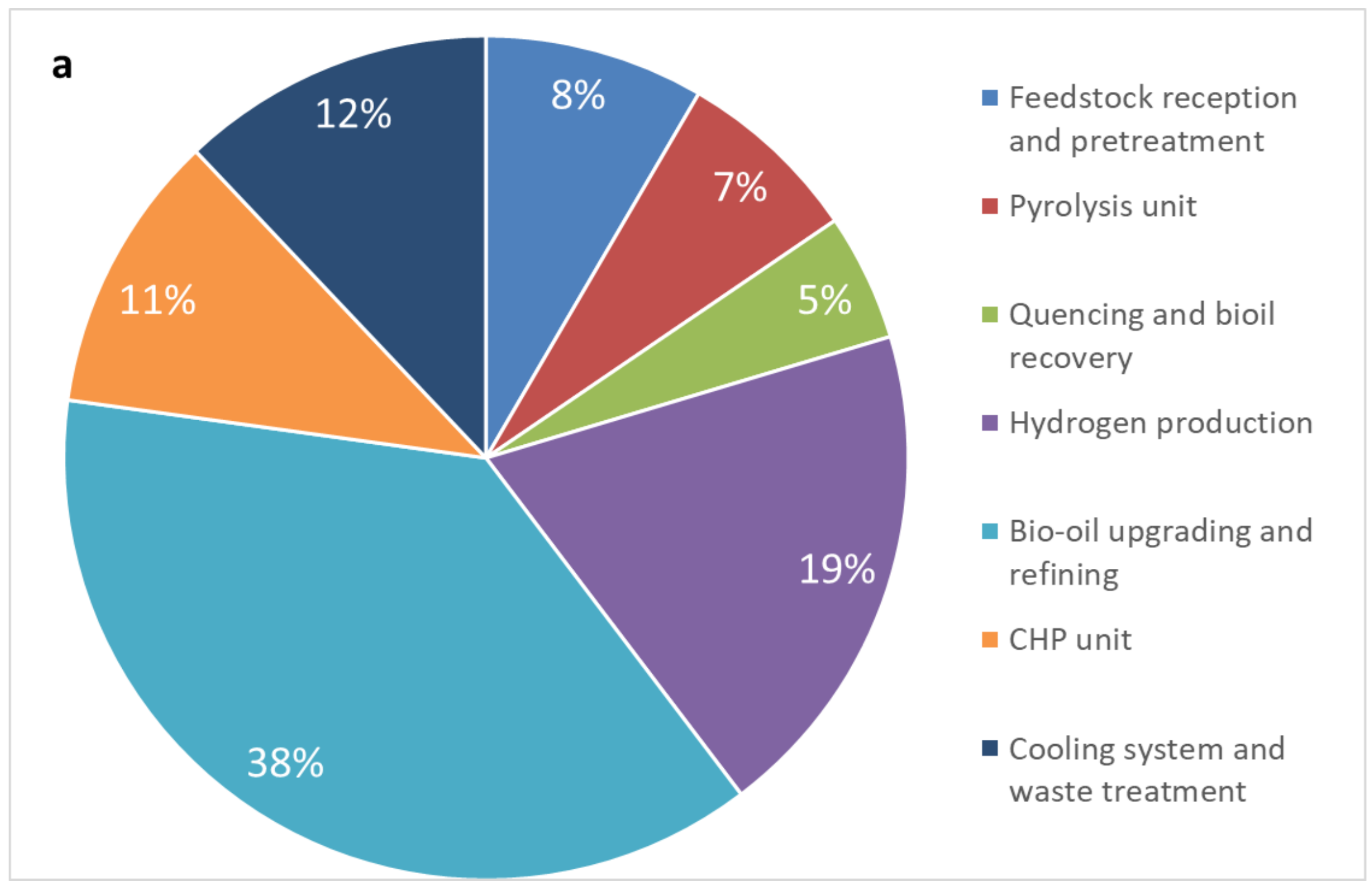




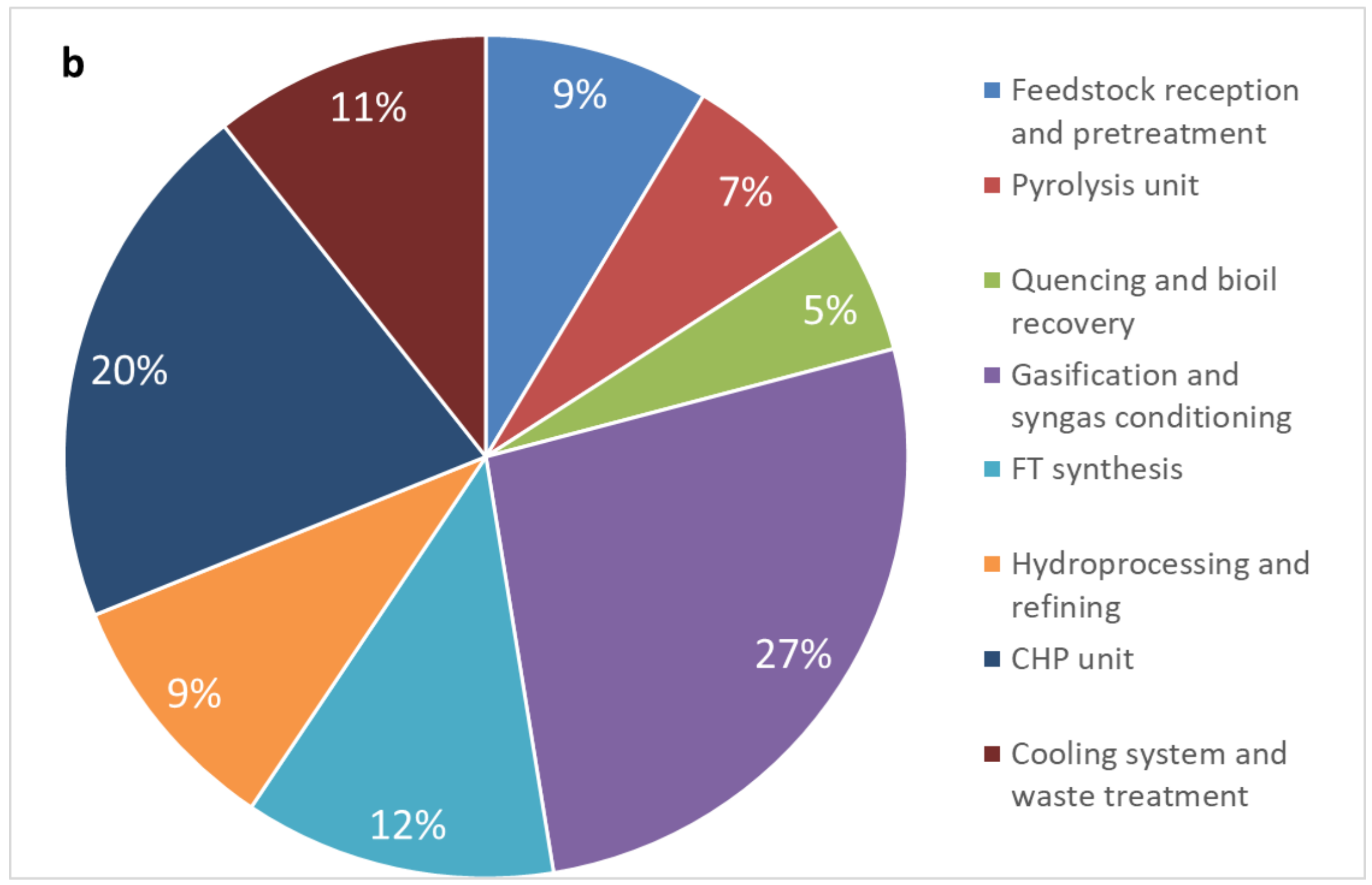




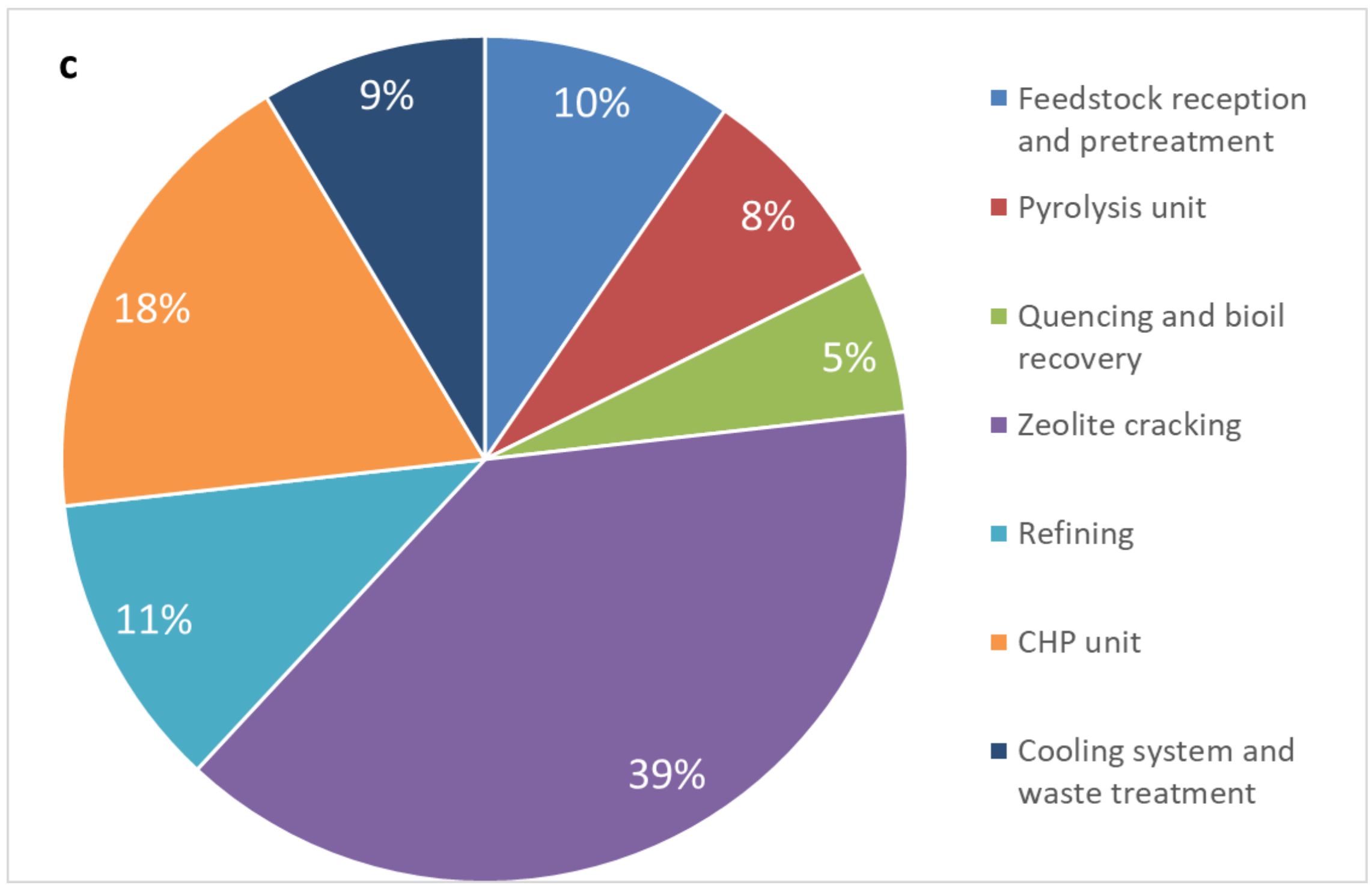

Figure 5. Breakdown of the equipment cost for each case $(a \rightarrow H P, b \rightarrow G+F T$ and $c \rightarrow Z C)$ 


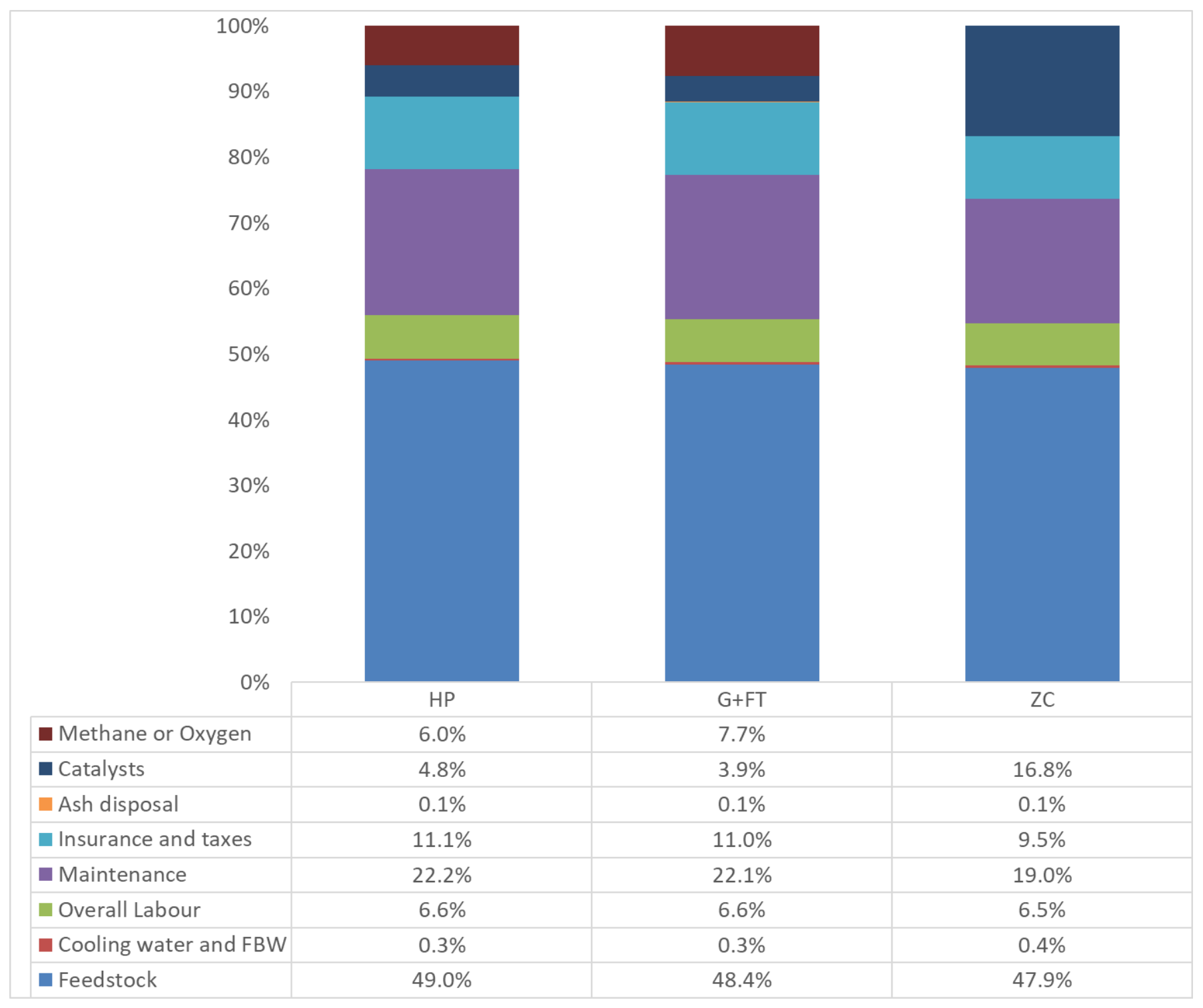

Figure 6. OPEX breakdown for each case 


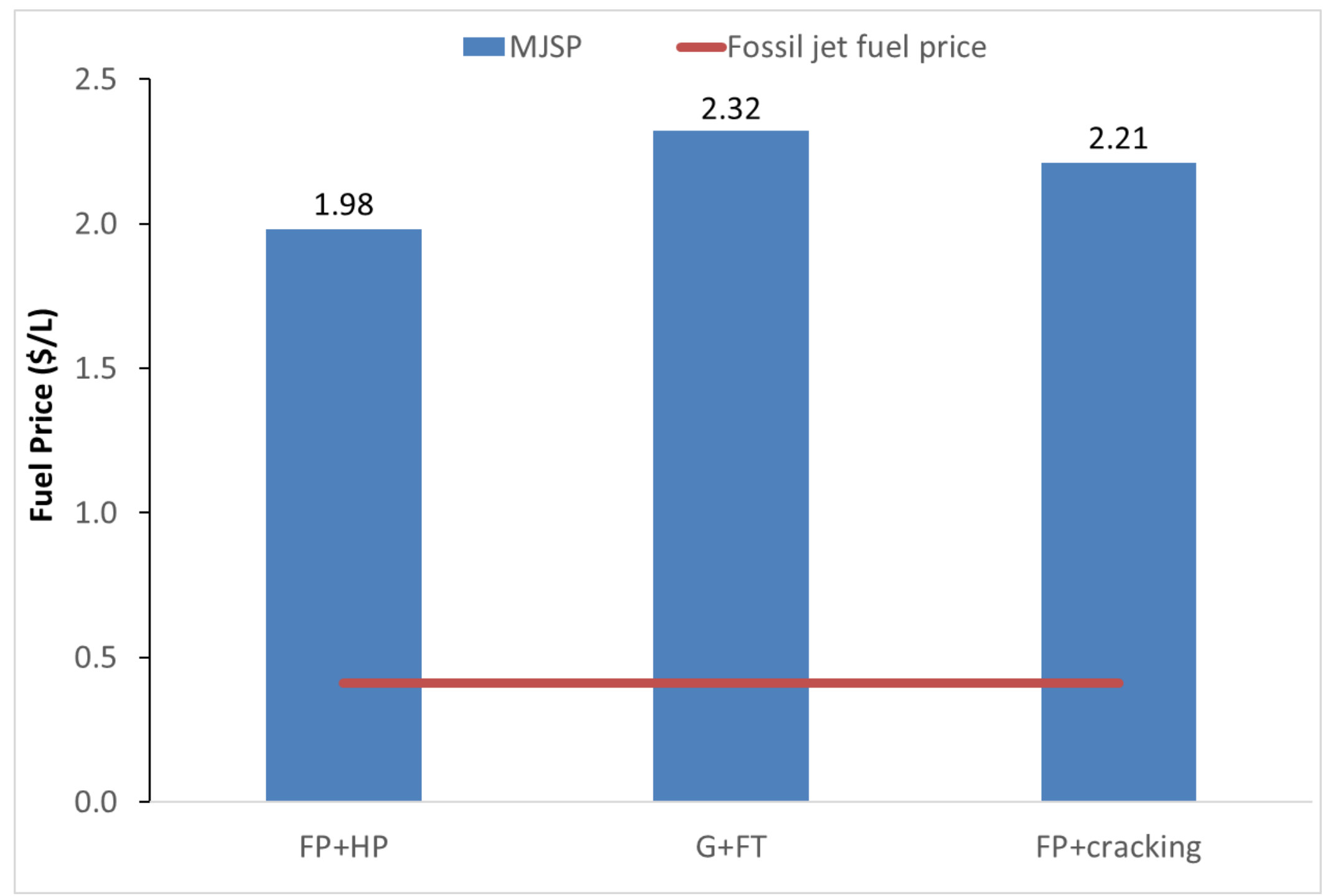

Figure 7. Minimum jet fuel prices for each case. The fossil jet fuel price is shown for comparisons 
a

CAPEX (-30\%:Nominal:+30\%)

Feedstock price (-20\%:Nominal:+20\%)

Bio-oil yield (70\%:Nominal:50\%)

Raw materials price (-20\%:Nominal:+20\%)

Electricity price (0.1:Nominal:0.04\$/kWh

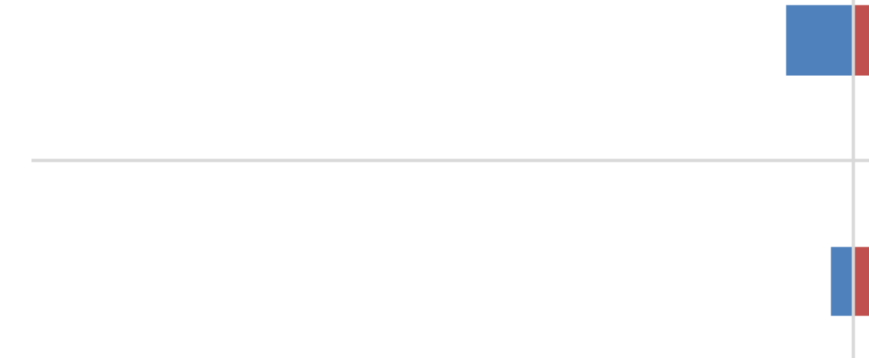

1.4

1.6

1.8

2

2.2

2.4

$\operatorname{MJSP}(\$ / L)$ 
b

CAPEX (-30\%:Nominal:+30\%)

Feedstock price (-20\%:Nominal:+20\%)

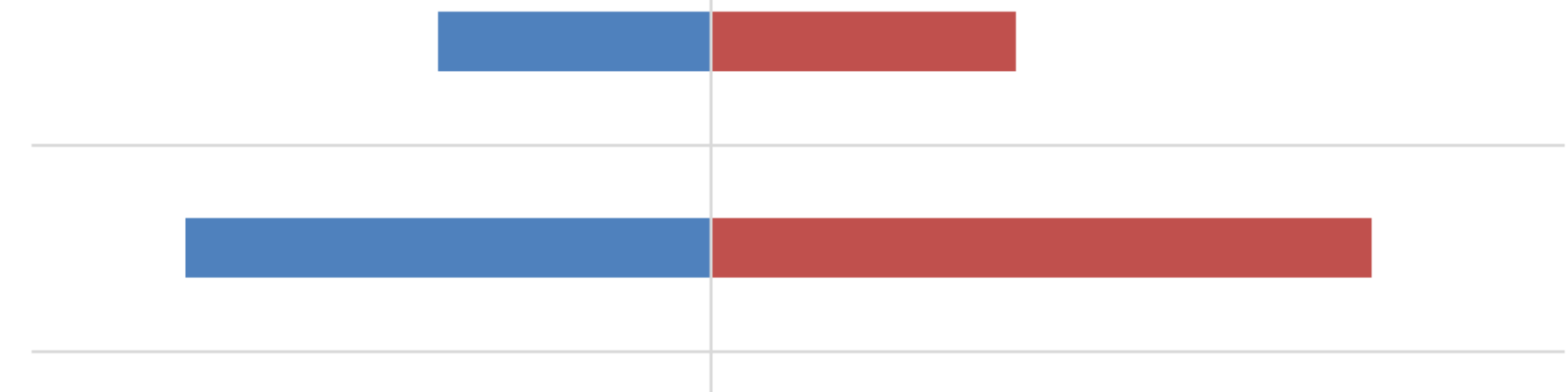

Raw materials price (-20\%:Nominal:+20\%)

Electricity price (0.1:Nominal:0.04 \$/kWh)

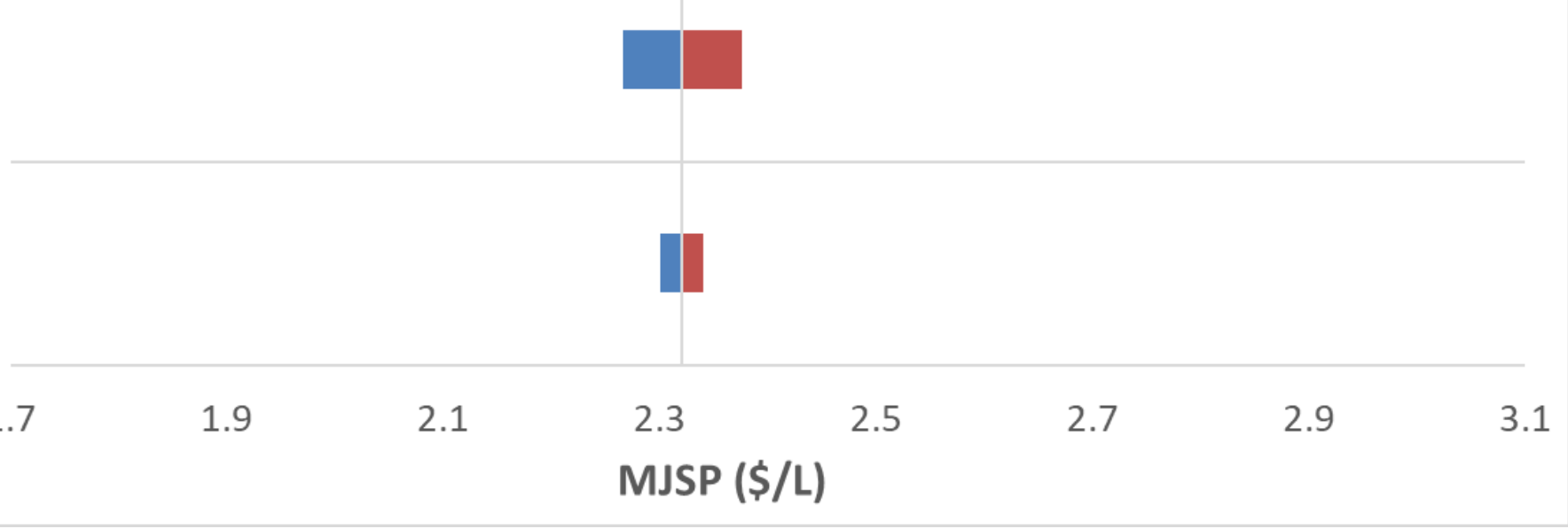




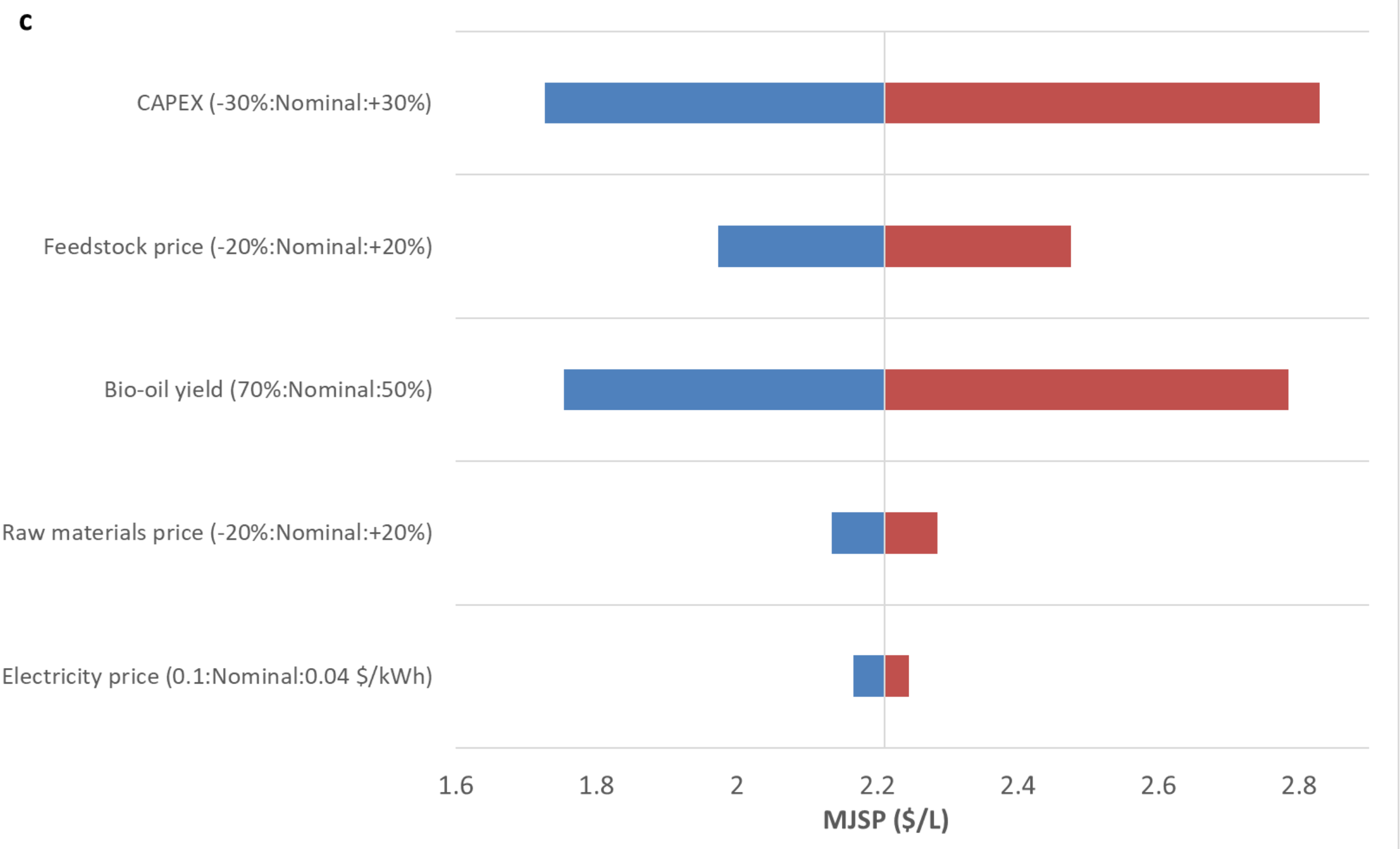

Figure 8. Sensitivity analysis on the MJSPs for each case $(a \rightarrow H P, b \rightarrow G+F T$ and $c \rightarrow Z C)$ 


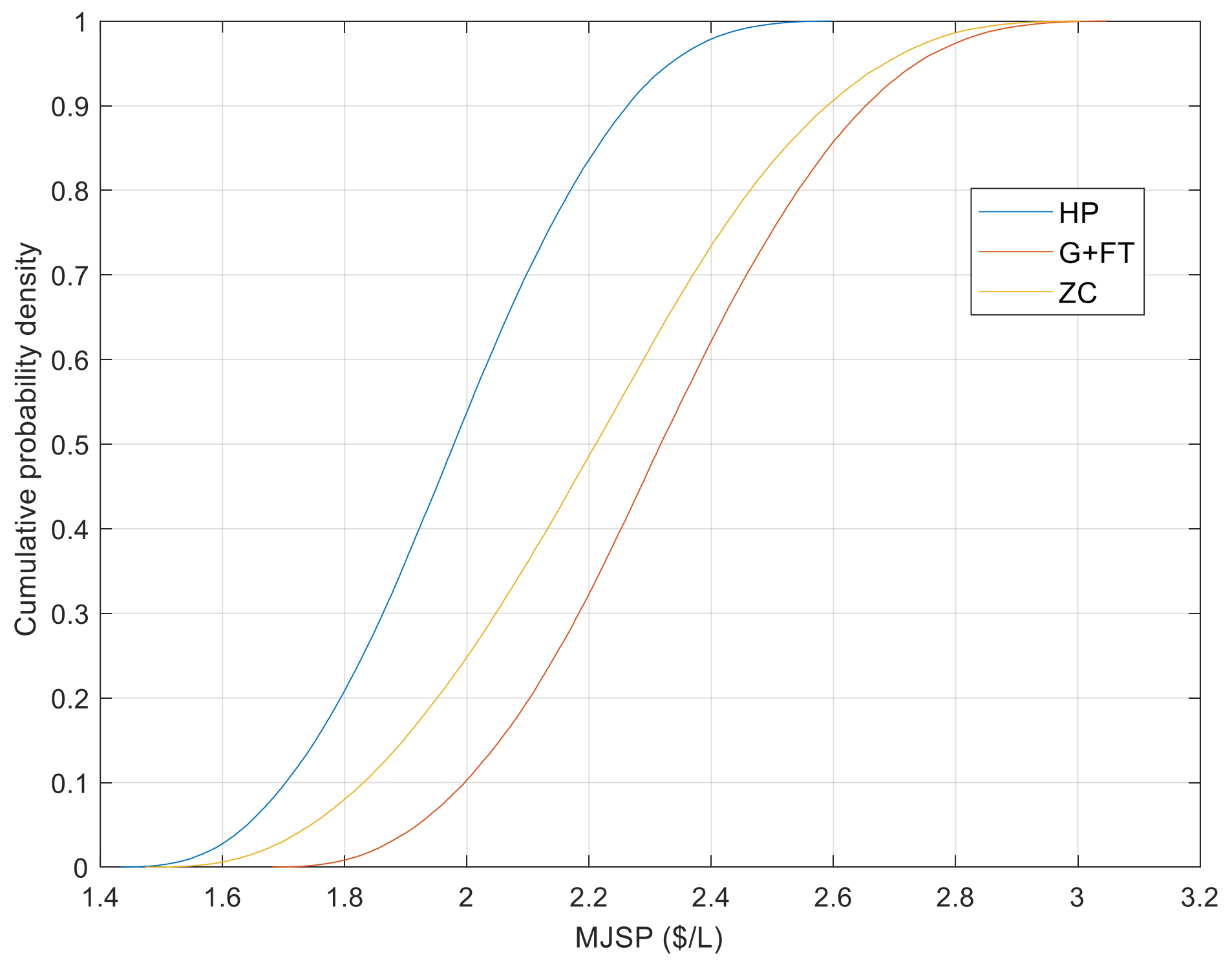

Figure 9. Monte Carlo analysis on the MJSP for each case 


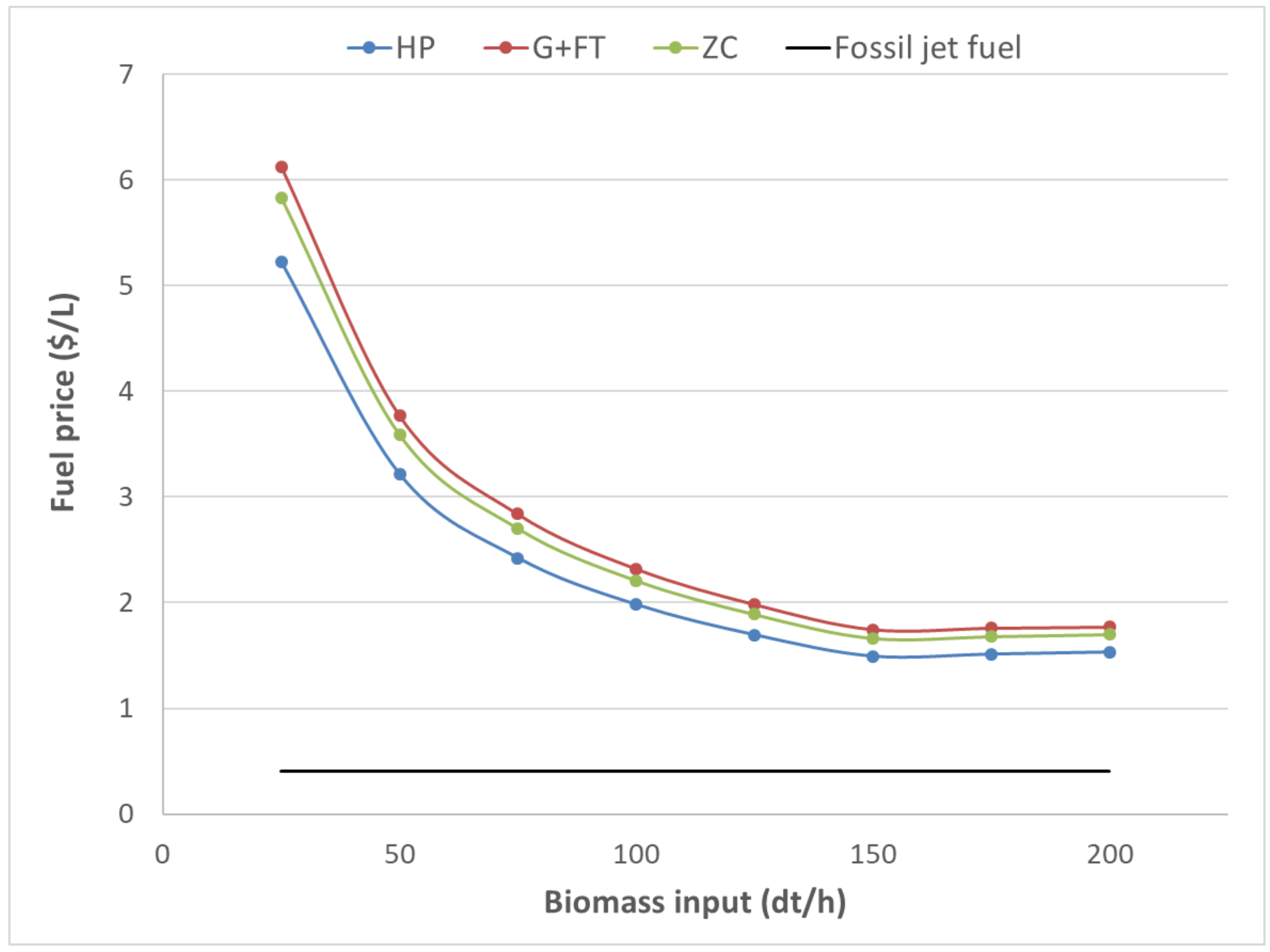

Figure 10. Effect of the plant capacity on the MJSPs for each case. The fossil jet fuel price is shown for comparisons 


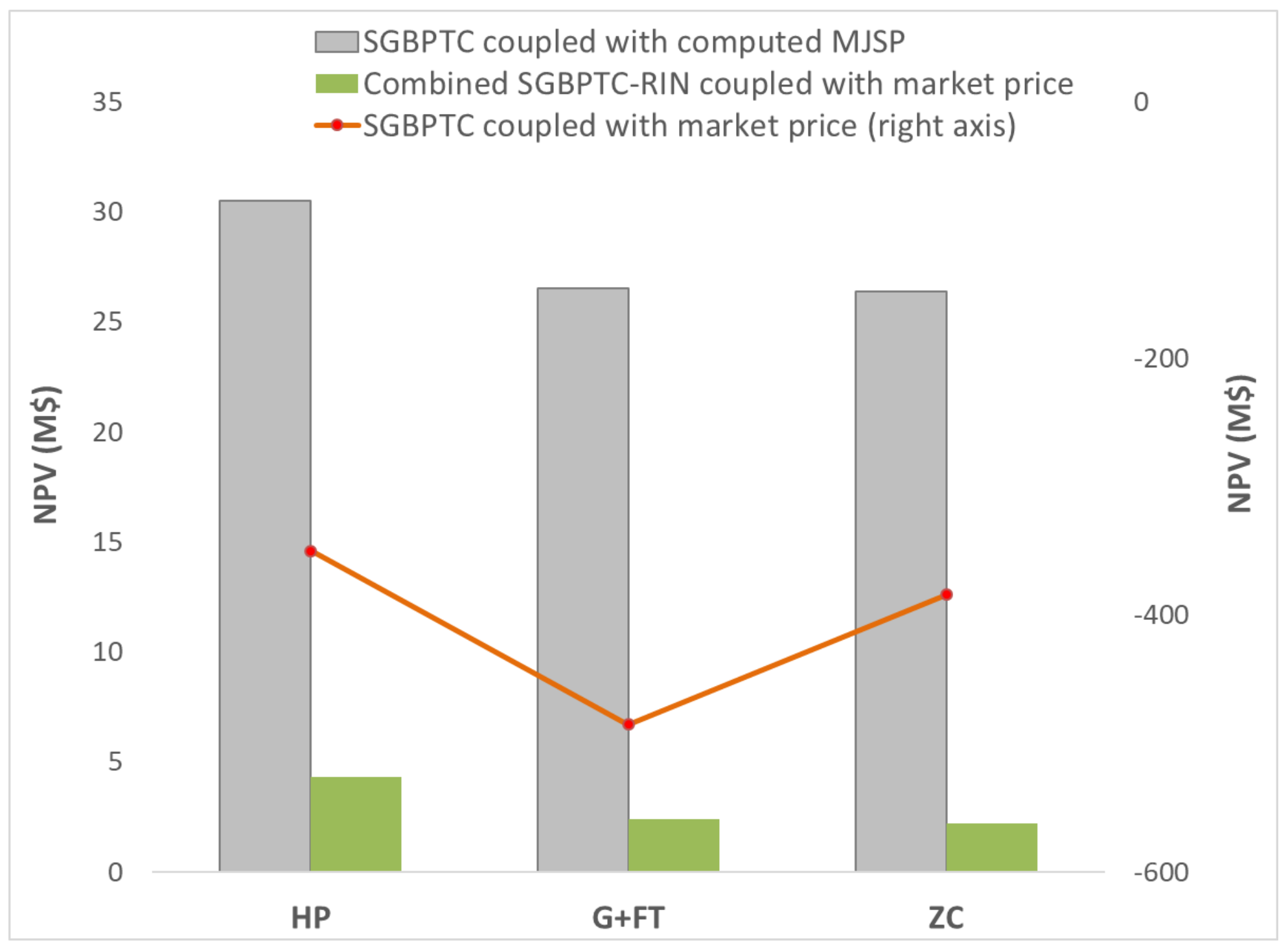

Figure 11. Effect of policy incentives on the NPV for each case 